\title{
Synthesis and molecular docking of novel non-cytotoxic anti- angiogenic sulfonyl coumarin derivatives against hepatocellular carcinoma cells in vitro
}

\author{
Eslam R. El- Sawy ${ }^{1}$, Manal Sh Ebaid ${ }^{1}$, Hanaa M. Rady ${ }^{1}$, Aziza B. Shalby ${ }^{2}$, Khadiga M. Ahmed ${ }^{1}$, Heba M. Abo-Salem ${ }^{1 *}$ \\ ${ }^{1}$ Chemistry of Natural Compound Department, National Research Centre, 12622 Dokki, Giza, Egypt. \\ ${ }^{2}$ Hormones Department, Medical Research Division, National Research Centre, 12622 Dokki, Giza, Egypt.
}

\section{ARTICLE INFO}

Article history:

Received on: 20/11/2016

Accepted on: $14 / 12 / 2016$

Available online: 27/02/2017

Key words:

Coumarin sulfonyl chlorides,

non-cytotoxic, anti-

angiogenic, molecular

docking.

\begin{abstract}
Resistance to conventional cytotoxic therapeutics, emphasize the need for efforts to develop non-cytotoxic targeted molecular therapies directed against the pathways involved in the angiogenesis. In this work a new series of coumarin derivatives was synthesized starting from 2-oxo- $2 \mathrm{H}$-coumarin-6-sulfonyl chloride (1), 6nitro-2-oxo-2H-coumarin-3-sulfonyl chloride (10) and 6-amino coumarin-2-one (19). The tested compounds $\mathbf{4}$, $5,8,12,13$ and 14 were non-cytotoxic against hepatocellular carcinoma cells (HepG2) using MMT. These noncytotoxic compounds were evaluated as anti-angiogenic agent. Results revealed that compounds $\mathbf{8}$ and $\mathbf{1 2}$ exhibited MMP-independent anti-migratory activity, while compounds 4, 5, 8, 13 and 14 induced MMPdependent anti-migratory activity against hepatocellular carcinoma. Therefore, these coumarin molecules can be utilized as lead compounds to develop potential non-toxic angiogenesis inhibitors and small molecular ligands to target (HepG2). Compound $\mathbf{4}$ considered a promising anti-angiogenic agent, where it exhibited MMP-dependent anti-migratory activity and down regulated CD105. Furthermore, the molecular docking of the tested compounds was carried out in order to investigate their binding pattern with the prospective target, MMP2 (PDB-code: 1HOV). The docking results indicate that all tested compounds exhibited better docking score and good fitting inside the active side of MMP-2 (PDB-code: 1HOV) which was in concomitant with biological results.
\end{abstract}

\section{INTRODUCTION}

Angiogenesis is a normal process, required for normal tissue repair and growth (Ucuzianet al., 2010). Angiogenesis is the key factor in the development and metastasis of a variety of tumor types, and represent an important hallmark of malignant disease (Ma and Waxman, 2008). The inhibition of tumor growth by anti-angiogenic drugs has been achieved both in preclinical studies and in clinical trials, where promising antitumor responses have been reported for a variety of antiangiogenic agents (eg. bevacizumab, sunitinib, and sorafenib) (Vasudev and Reynolds 2014). Overall, the survival benefits of anti-angiogenic drugs leading to increased interest in developing

\footnotetext{
* Corresponding Author

Heba M. Abo-Salem, Chemistry of Natural Compounds Department, National Research Centre, 12311 Dokki, Giza Egypt; Tel: +202 33371362, Fax: +20 333709 31; E-mail: hb_abosalem @yahoo.com
}

more effective ways to combine antiangiogenic drugs with traditional cytotoxic chemotherapies (Folkman 2007; Cesca 2013). Over the last years, several non-cytotoxic molecular targeted therapies have been developed against growth factor receptors and tumor angiogenesis (Idbaih et al., 2008). Coumarins constitute a class of compounds belong to the family of lactone, which are found widely in nature (Keating and O'Kennedy 1997), and possess diverse biological activities (Al-Bayati et al., 2010), for example, antimicrobial (Sahoo et al., 2015), anti-inflammatory (Kirsch et al., 2016), antioxidant (Arora et al., 2014) and antiviral including human immunodeficiency virus (HIV) (Curini et al., 2003; Završnik et al., 2011). In cancer drug development arena, coumarin-type compounds have been reported to bosses marked cytotoxic activities (Kostova et al., 2005; Jeon et al., 2015), in addition act as novel angiogenesis inhibitors. From this perspective, the present work is aimed to illustrate the anticancer activity of novel sulfonyl coumarin derivatives. 
In addition we attempted to explore the probability of the most promising anti-angiogenic compounds to inhibit matrix mettaloproteinase enzyme via molecular docking study of these compounds against the active site of the protein molecular surface of MMP-2 (PDB ID: 1HOV)

\section{MATERIALS AND METHODS}

\section{Instruments and reagents}

Melting points were determined on the digital melting point apparatus (Electro thermal 9100, Electro thermal Engineering Ltd, serial No. 8694, Rochford, United Kingdom) and are uncorrected. The micro analytical data were achieved on a Perkin-Elmer 2400 analyzer (Perkin-Elmer, 940 Winter Street, Waltham, Massachusetts 02451 , USA) and were found within \pm 0.4 $\%$ of the theoretical values. IR spectra were recorded on a PerkinElmer 1600 Fourier Transform Infrared Spectrophotometer using $\mathrm{KBr}$ discs. The ${ }^{1} \mathrm{H}$ NMR spectra were measured with a Bruker Avance digital spectrometer (BRUKER BioSpin GMBH Silberstreifen D-76287 Rheinstetten, Germany) (500 MHz) in DMSO- $d 6$, and chemical shifts were recorded in $\delta$ ppm relative to TMS as internal standard (all $\mathrm{NH}_{2}$ and $\mathrm{NH}$ recorded for the compounds were $\mathrm{D}_{2} \mathrm{O}$-exchangeable).Mass spectra (EI) were recorded at $70 \mathrm{eV}$ with JEOL-JMS-AX500 mass spectrometer (JEOL Ltd. 1-2, Musashino 3-chome Akishima, Tokyo 196-8558, Japan). All reagents and solvents were of commercial grade. 2oxo-2H-coumarin-6-sulfonyl chloride (1) (Ismail et al., 1989), 6nitro-2-oxo-2H-coumarin-3-sulfonyl chloride (10) (Abd El-Hafez et al., 1994), 2-cyanoacetic acid hydrazide (Heibron 1965), 2'acetyl-2-cyanoacetohydrazide (Graham et al., 1949), 3-amino-5pyrazolone (Callejo et al., 1990), and arylidene malononitriles (Kassem et al., 2012) were prepared as reported.

\section{Synthesis}

N'-(2-Cyanoacetyl)-2-oxo-2H-chromene-6-sulfonohydrazide (2)

A mixture of 2-oxo-2H-chromene-6-sulfonyl chloride (1) $(2.4 \mathrm{~g}, 0.01 \mathrm{~mol})$ and 2-cyanoacetic acid hydrazide (1.3 g, 0.01 $\mathrm{mol})$ in absolute ethanol $(20 \mathrm{ml})$ containing triethylamine $(1 \mathrm{ml})$ was stirred for $3 \mathrm{~h}$ at room temperature. The formed precipitate was filtered off, washed with water, air dried and crystallized from dry ethanol. Yield: $62 \%$; MP: $157-9{ }^{\circ} \mathrm{C}$; IR $\left(\mathrm{KBr}, v_{\max }, \mathrm{cm}^{-1}\right) 3230$, $3165(\mathrm{NH}), 2205(\mathrm{CN}), 1705,1654(\mathrm{C}=\mathrm{O}), 1525(\mathrm{C}=\mathrm{C}), 1385$, $1117\left(\mathrm{SO}_{2}-\mathrm{N}\right), 1135,1010$ (C-O-C); ${ }^{1} \mathrm{H}$ NMR (500 MHz, DMSO$\left.d_{6}\right): \delta 9.52(1 \mathrm{H}, \mathrm{s}, \mathrm{NH}), 8.28(1 \mathrm{H}, \mathrm{s}, \mathrm{H}-5), 8.07$ (1H, d, H-7), 7.81 (1H, d, H-4), 7.44 (1H, d, H-8), $7.15(1 \mathrm{H}, \mathrm{s}, \mathrm{NH}), 6.32(1 \mathrm{H}, \mathrm{d}, \mathrm{H}-$ 3) $4.15 \mathrm{ppm}\left(2 \mathrm{H}, \mathrm{s}, \mathrm{CH}_{2}\right)$; $\mathrm{MS}(\mathrm{m} / \mathrm{z})$ : $307\left[\mathrm{M}^{+}\right]$; Anal. $\mathrm{C}_{12} \mathrm{H}_{9} \mathrm{~N}_{3} \mathrm{O}_{5} \mathrm{~S}$ (307.28): Calcd: C, 46.90; H, 2.95; N, 13.67; Found: C, 46.81; H, $2.84 ; \mathrm{N}, 13.52$.

\section{5-Amino-1-(2-oxo-2H-chromene-6-sulfonyl)-1H-pyrazol-3(2H)- one (3)}

A solution of compound 2 (2.4 g, $0.01 \mathrm{~mol})$ in absolute ethanol $(20 \mathrm{ml})$ containing triethylamine $(1 \mathrm{ml})$ was heated under reflux for $3 \mathrm{~h}$. After cooling, the solid that formed was filtered off, washed with water, air dried and crystallized from dry ethanol. Yield: 65\%; MP: $184 \mathrm{dec}{ }^{\circ} \mathrm{C}$; IR (KBr, $\left.v_{\max }, \mathrm{cm}^{-1}\right) 3410,3325$ $\left(\mathrm{NH}_{2}\right), 3265(\mathrm{NH}), 1710,1696(\mathrm{C}=\mathrm{O}), 1556(\mathrm{C}=\mathrm{C}), 1375,1126$ $\left(\mathrm{SO}_{2}-\mathrm{N}\right), 1133,1019$ (C-O-C); ${ }^{1} \mathrm{H}$ NMR (500 MHz, DMSO-d $\left.{ }_{6}\right): \delta$ 10.09 (1H, s, NH), 8.30 (1H, s, H-5), $8.12(1 \mathrm{H}, \mathrm{d}, \mathrm{H}-7), 7.81(1 \mathrm{H}$, d, H-4), $7.45(1 \mathrm{H}, \mathrm{d}, \mathrm{H}-8), 6.41(1 \mathrm{H}, \mathrm{d}, \mathrm{H}-3), 4.54(1 \mathrm{H}, \mathrm{s}$, pyrazolyl H-4), 2.16 ppm (2H, s, $\left.\mathrm{NH}_{2}\right)$; $\mathrm{MS}(\mathrm{m} / \mathrm{z}): 307\left[\mathrm{M}^{+}\right]$; Anal. $\mathrm{C}_{12} \mathrm{H}_{9} \mathrm{~N}_{3} \mathrm{O}_{5} \mathrm{~S}$ (307.28): Calcd: C, 46.90; H, 2.95; N, 13.67; Found: C, 46.82; H, 2.81; N, 13.55 .

\section{1-Acetyl-5-amino- 4-(2-oxo-2H-chromene-6-sulfonyl)-1,2- dihydro-pyrazol-3-one (4)}

A mixture of $\mathbf{1}(2.4 \mathrm{~g}, 0.01 \mathrm{~mol})$ and 2'-acetyl-2cyanoacetohydrazide $(0.14 \mathrm{~g}, 0.01 \mathrm{~mol})$ in absolute ethanol (20 $\mathrm{ml})$ containing triethylamine $(1 \mathrm{ml})$ was stirred for $3 \mathrm{~h}$ at room temperature, the formed precipitate was filtered off, washed with water, air dried and crystallized from dry ethanol. Yield: $85 \%$; MP: $102-4{ }^{\circ} \mathrm{C}$; IR (KBr, $\left.v_{\max }, \mathrm{cm}^{-1}\right) 3426,3346\left(\mathrm{NH}_{2}\right), 3165(\mathrm{NH})$, 1705, 1686, $1665(\mathrm{C}=\mathrm{O}), 1523(\mathrm{C}=\mathrm{C}), 1365,1156\left(\mathrm{SO}_{2}\right), 1142$, 1026 (C-O-C); ${ }^{1} \mathrm{H}$ NMR (500 MHz, DMSO- $\left.d_{6}\right): \delta 9.55(1 \mathrm{H}, \mathrm{s}$, $\mathrm{NH}), 8.40$ (1H, s, H-5), 8.23 (1H, d, H-7), 7.79 (1H, d, H-4), 7.52 (1H, d, H-8), $6.51(1 \mathrm{H}, \mathrm{d}, \mathrm{H}-3), 4.25\left(2 \mathrm{H}, \mathrm{s}, \mathrm{NH}_{2}\right), 1.62 \mathrm{ppm}(3 \mathrm{H}$, s, $\left.\mathrm{CH}_{3}\right)$; $\mathrm{MS}(\mathrm{m} / \mathrm{z}): 349\left[\mathrm{M}^{+}\right]$; Anal. $\mathrm{C}_{14} \mathrm{H}_{11} \mathrm{~N}_{3} \mathrm{O}_{6} \mathrm{~S}$ (349.32): Calcd: C, 48.14; H, 3.17; N, 12.03; Found: C, 48.03; H, 3.01; N, 11.90.

\section{2-Oxo-2H-chromene-6-sulfonic acid (5-oxo-4,5-dihydro-1H- pyrazol-3-yl)amide (5)}

A mixture of 1 (2.4 g, $0.01 \mathrm{~mol})$ and 3-amino-5pyrazolone $(0.99 \mathrm{~g}, 0.01 \mathrm{~mol})$ in absolute ethanol $(20 \mathrm{ml})$ containing triethylamine $(1 \mathrm{ml})$ was stirred for $3 \mathrm{~h}$ at room temperature, the formed precipitate was filtered off, washed with water, air dried and crystallized from dry ethanol. Yield: 77\%; MP: $254-6{ }^{\circ} \mathrm{C}$; IR ( $\left.\mathrm{KBr}, v_{\max }, \mathrm{cm}^{-1}\right) 3326(\mathrm{NH}), 1705,1688(\mathrm{C}=\mathrm{O})$, $1618(\mathrm{C}=\mathrm{N}), 1565(\mathrm{C}=\mathrm{C}), 1376,1145\left(\mathrm{SO}_{2}-\mathrm{N}\right), 1133,1106(\mathrm{C}-\mathrm{O}-$ C); ${ }^{1} \mathrm{H}$ NMR (500 MHz, DMSO- $\left.d_{6}\right): \delta 9.81(1 \mathrm{H}, \mathrm{s}, \mathrm{NH}), 8.28(1 \mathrm{H}$, s, H-5), 8.01 (1H, d, H-7), 7.66 (1H, d, H-4), 7.37 (1H, d, H-8), 6.66 (1H, d, H-3), 4.54 (2H, s, $\left.\mathrm{CH}_{2}\right), 2.41 \mathrm{ppm}(1 \mathrm{H}, \mathrm{s}, \mathrm{NH})$; MS $(\mathrm{m} / \mathrm{z}): 307\left[\mathrm{M}^{+}\right]$; Anal. $\mathrm{C}_{12} \mathrm{H}_{9} \mathrm{~N}_{3} \mathrm{O}_{5} \mathrm{~S}$ (307.28): Calcd: $\mathrm{C}, 46.90 ; \mathrm{H}$, 2.95 ; N, 13.67; Found: C, 46.79; H, 3.11; N, 13.53 .

\section{Synthesis of pyrano(2,3-c)pyrazoles 6a-d}

A solution of compound $5(3.06 \mathrm{~g}, 0.01 \mathrm{~mol})$ and an appropriate arylidene malononitriles $(0.01 \mathrm{~mol})$ in dry 1,4-dioxane containing triethylamine $(1 \mathrm{ml})$ was refluxed for $4-6 \mathrm{~h}$. After cooling, the solid that formed was filtered off, washed with water, air dried and crystallized from dry ethanol.

\section{2-Oxo-2H-chromene-6-sulfonic acid (6-amino-5-cyano-4- phenylpyrano(2,3-c)pyrazol-3-yl)amide (6a)}

Yield: 55\%; MP: $221-3{ }^{\circ} \mathrm{C}$; IR (KBr, $\left.v_{\max }, \mathrm{cm}^{-1}\right) 3366$ $\left(\mathrm{NH}_{2}\right), 3153(\mathrm{NH}), 2207(\mathrm{CN}), 1710(\mathrm{C}=\mathrm{O}), 1618(\mathrm{C}=\mathrm{N}), 1545$ $(\mathrm{C}=\mathrm{C}), 1385,1128\left(\mathrm{SO}_{2}-\mathrm{N}\right), 1117,1022(\mathrm{C}-\mathrm{O}-\mathrm{C}) ;{ }^{1} \mathrm{H}$ NMR $(500$ MHz, DMSO-d $\left.d_{6}\right): \delta 10.85(1 \mathrm{H}, \mathrm{s}, \mathrm{NH}), 9.35\left(2 \mathrm{H}, \mathrm{s}, \mathrm{NH}_{2}\right), 8.53-$ 7.06 (9H, m, Ar-H), 6.82 ppm (1H, d, H-3); MS (m/z): $459\left[\mathrm{M}^{+}\right]$; 
Anal. $\mathrm{C}_{22} \mathrm{H}_{13} \mathrm{~N}_{5} \mathrm{O}_{5} \mathrm{~S}$ (459.43): Calcd: C, 57.51; H, 2.85; N, 15.24; Found: C, 57.39; H, 2.73; N, 15.09.

\section{2-Oxo-2H-chromene-6-sulfonic acid (6-amino-4-(4- chlorophenyl)-5-cyano-pyrano(2,3-c)pyrazol-3-yl) amide (6b)}

Yield: 56\%; MP: $123-5{ }^{\circ} \mathrm{C}$; IR $\left(\mathrm{KBr}, v_{\max }, \mathrm{cm}^{-1}\right) 3422$ $\left(\mathrm{NH}_{2}\right), 3175(\mathrm{NH}), 2210(\mathrm{CN}), 1725(\mathrm{C}=\mathrm{O}), 1620(\mathrm{C}=\mathrm{N}), 1555$ $(\mathrm{C}=\mathrm{C}), 1366,1132\left(\mathrm{SO}_{2}-\mathrm{N}\right), 1120,1052$ (C-O-C), 725 (C-Cl); MS $(\mathrm{m} / \mathrm{z}): 493 / 495\left[\mathrm{M}^{+} / \mathrm{M}^{+}+2\right]$; Anal. $\mathrm{C}_{22} \mathrm{H}_{12} \mathrm{ClN}_{5} \mathrm{O}_{5} \mathrm{~S}$ (493.88): Calcd: C, 53.50; H, 2.45; N, 14.18; Found: C, 53.61; H, 2.33; N, 14.04.

\section{2-Oxo-2H-chromene-6-sulfonic acid (6-amino-4-(4- hydroxyphenyl)-5-cyano-pyrano(2,3-c)pyrazol-3-yl) amide (6c)}

Yield: 60\%; MP: $236 \mathrm{dec} .{ }^{\circ} \mathrm{C}$; IR $\left(\mathrm{KBr}, v_{\max }, \mathrm{cm}^{-1}\right) 3445$ $(\mathrm{OH}), 3399\left(\mathrm{NH}_{2}\right), 3169(\mathrm{NH}), 2212(\mathrm{CN}), 1705(\mathrm{C}=\mathrm{O}), 1620$ $(\mathrm{C}=\mathrm{N}), 1582(\mathrm{C}=\mathrm{C}), 1362,1128\left(\mathrm{SO}_{2}-\mathrm{N}\right), 1117,1109(\mathrm{C}-\mathrm{O}-\mathrm{C}) ;{ }^{1} \mathrm{H}$ NMR (500 MHz, DMSO-d $\left.d_{6}\right): \delta 13.05(1 \mathrm{H}, \mathrm{s}, \mathrm{OH}), 8.95(1 \mathrm{H}, \mathrm{s}$, $\mathrm{NH}), 8.62-7.10(8 \mathrm{H}, \mathrm{m}, \mathrm{Ar}-\mathrm{H}), 6.72(1 \mathrm{H}, \mathrm{d}, \mathrm{H}-3), 2.16 \mathrm{ppm}(2 \mathrm{H}$, s, $\left.\mathrm{NH}_{2}\right)$; $\mathrm{MS}(\mathrm{m} / \mathrm{z}): 475\left[\mathrm{M}^{+}\right]$; Anal. $\mathrm{C}_{22} \mathrm{H}_{13} \mathrm{~N}_{5} \mathrm{O}_{6} \mathrm{~S}$ (475.43): Calcd: C, 55.58; H, 2.76; N, 14.73; Found: C, 55.46; H, 2.80; N, 14.83.

\section{2-Oxo-2H-chromene-6-sulfonic acid (6-amino-4-(2-nitrophenyl)-} 5-cyano-pyrano(2,3-c)pyrazol-3-yl) amide (6d):

Yield: 63\%; MP: $142-4{ }^{\circ} \mathrm{C}$; IR $\left(\mathrm{KBr}, v_{\max }, \mathrm{cm}^{-1}\right) 3386$, $3295\left(\mathrm{NH}_{2}\right), 3212(\mathrm{NH}), 2207(\mathrm{CN}), 1710(\mathrm{C}=\mathrm{O}), 1618(\mathrm{C}=\mathrm{N})$, $1552(\mathrm{C}=\mathrm{C}), 1368,1135\left(\mathrm{SO}_{2}-\mathrm{N}\right), 1126,1105(\mathrm{C}-\mathrm{O}-\mathrm{C}) ;{ }^{1} \mathrm{H}$ NMR $\left(500 \mathrm{MHz}, \mathrm{DMSO}-d_{6}\right): \delta 9.15(1 \mathrm{H}, \mathrm{s}, \mathrm{NH}), 8.66-7.15(8 \mathrm{H}, \mathrm{m}, \mathrm{Ar}-$ $\mathrm{H}), 6.53$ (1H, d, H-3), 1.69 ppm (2H, s, $\left.\mathrm{NH}_{2}\right)$; MS (m/z): $504\left[\mathrm{M}^{+}\right]$; Anal. $\mathrm{C}_{22} \mathrm{H}_{12} \mathrm{~N}_{6} \mathrm{O}_{7} \mathrm{~S}$ (504.43): Calcd: C, 52.38; H, 2.40; N, 16.66; Found: C, 52.21; H, 2.52; N, 16.56 .

\section{2-(2-Oxo-2H-chromene-6-sulfonyl)malononitrile (7)}

A mixture of $1(2.4 \mathrm{~g}, 0.01 \mathrm{~mol})$ and malononitrile $(0.6 \mathrm{~g}$, $0.01 \mathrm{~mol})$ in dry ethanol $(20 \mathrm{ml})$ containing triethylamine $(1 \mathrm{ml})$ was refluxed for $3 \mathrm{~h}$. The solid that formed was filtered off, washed with water, air dried and crystallized from dry ethanol. Yield: 76\%; MP: $121-3{ }^{\circ} \mathrm{C}$; IR (KBr, $\left.v_{\max }, \mathrm{cm}^{-1}\right) 2195(\mathrm{CN}), 1737$ $(\mathrm{C}=\mathrm{O}), 1620(\mathrm{C}=\mathrm{C}), 1366,1171\left(\mathrm{SO}_{2}\right), 1111(\mathrm{C}-\mathrm{O}-\mathrm{C}) ; \mathrm{MS}(\mathrm{m} / \mathrm{z})$ : $274\left[\mathrm{M}^{+}\right]$; Anal. $\mathrm{C}_{12} \mathrm{H}_{6} \mathrm{~N}_{2} \mathrm{O}_{4} \mathrm{~S}$ (274.25): Calcd: C, 52.55; H, 2.21; N, 10.21; Found: C, 52.62; H, 2.35; N, 10.14.

\section{6-(3,5-Diamino-4H-pyrazole-4-sulfonyl)chromen-2-one (8)}

To a solution of compound $7(0.01 \mathrm{~mol})$ in dry ethanol (10 ml) containing few drops of triethylamine, hydrazine hydrate 99\% (1 ml, $0.02 \mathrm{~mol}$ ) was added, and then stirred for $5 \mathrm{~h}$. After cooling, the reaction mixture was poured onto ice-water $(50 \mathrm{ml})$. The solid that formed was filtered off, air dried and crystallized from dry ethanol. Yield: 82\%; MP: $177 \mathrm{dec} .{ }^{\circ} \mathrm{C}$; IR $\left(\mathrm{KBr}, v_{\max }\right.$, $\left.\mathrm{cm}^{-1}\right) 3426\left(\mathrm{NH}_{2}\right), 1712(\mathrm{C}=\mathrm{O}), 1620(\mathrm{C}=\mathrm{N}), 1562(\mathrm{C}=\mathrm{C}), 1175$ $\left(\mathrm{SO}_{2}-\mathrm{C}\right), 1122,1009$ (C-O-C); ${ }^{1} \mathrm{H}$ NMR (500 MHz, DMSO- $\left.d_{6}\right): \delta$ 8.55 (1H, s, H-5), 8.37 (1H, d, H-7), $7.64(1 \mathrm{H}, \mathrm{d}, \mathrm{H}-4), 7.24(1 \mathrm{H}$, d, H-8), 6.46 (1H, d, H-3), $5.52\left(2 \mathrm{H}, \mathrm{s}, \mathrm{NH}_{2}\right), 3.72(1 \mathrm{H}, \mathrm{s}, \mathrm{CH}-$ pyrazole), 2.95 ppm (2H, s, $\left.\mathrm{NH}_{2}\right)$; $\mathrm{MS}(\mathrm{m} / \mathrm{z}): 306\left[\mathrm{M}^{+}\right]$; Anal.
$\mathrm{C}_{12} \mathrm{H}_{10} \mathrm{~N}_{4} \mathrm{O}_{4} \mathrm{~S}$ (306.30): Calcd: C, 47.06; H, 3.29; N, 18.29; Found: C, 47.12; H, 3.20; N, 18.35 .

\section{Synthesis of compounds 9a-c}

A mixture of compound $7(0.01 \mathrm{~mol})$ and urea, thiourea or guanidine hydrochloride $(0.01 \mathrm{~mol})$ in dry ethanol $(10 \mathrm{ml})$ containing triethylamine $(0.5 \mathrm{ml})$ was refluxed for $8-10 \mathrm{~h}$. After cooling, the reaction mixture was poured onto ice-water $(50 \mathrm{ml})$ and the solid that formed was filtered off, air dried and crystallized from dry ethanol.

\section{4,6-Diamino -5-(2-oxo-2H-chromene-6-sulfonyl)-5H-pyrimidin- 2-one $(9 a)$}

Yield: $83 \%$; MP: $173-5{ }^{\circ} \mathrm{C}$; IR (KBr, $\left.v_{\max }, \mathrm{cm}^{-1}\right)$ 3412, $3395\left(\mathrm{NH}_{2}\right), 1710,1692(\mathrm{C}=\mathrm{O}), 1622(\mathrm{C}=\mathrm{N}), 1575(\mathrm{C}=\mathrm{C}), 1345$, $1175\left(\mathrm{SO}_{2}-\mathrm{C}\right), 1124,1035(\mathrm{C}-\mathrm{O}-\mathrm{C}) ; \mathrm{MS}(\mathrm{m} / \mathrm{z}): 334\left[\mathrm{M}^{+}\right]$; Anal. $\mathrm{C}_{13} \mathrm{H}_{10} \mathrm{~N}_{4} \mathrm{O}_{5} \mathrm{~S}$ (334.31): Calcd: C, 46.71; H, 3.02; N, 16.76; Found: C, 46.63; H, 2.92; N, 16.60 .

\section{4,6-Diamino- 5-(2-thioxo-2H-chromene-6-sulfonyl)-5H- pyrimidin-2-one (9b)}

Yield: 79\%; MP: $210-2{ }^{\circ} \mathrm{C}$; IR (KBr, $\left.v_{\max }, \mathrm{cm}^{-1}\right) 3425$ (br. $\left.\mathrm{NH}_{2}\right), 1705(\mathrm{C}=\mathrm{O}), 1620(\mathrm{C}=\mathrm{N}), 1545(\mathrm{C}=\mathrm{C}), 1245(\mathrm{C}=\mathrm{S}), 1355$, 1135 ( $\left.\mathrm{SO}_{2}-\mathrm{C}\right), 1133,1101$ (C-O-C); ${ }^{1} \mathrm{H}$ NMR (500 MHz, DMSO$\left.d_{6}\right): \delta 8.93$ (1H, s, H-5), $8.41(1 \mathrm{H}, \mathrm{d}, \mathrm{H}-7), 8.24(1 \mathrm{H}, \mathrm{d}, \mathrm{H}-4), 7.59$ (1H, d, H-8), 6.89 (1H, d, H-3), 5.57 (1H, s, CH-pyrimidine), 3.04 $\left(2 \mathrm{H}, \mathrm{s}, \mathrm{NH}_{2}\right), 2.31$ ppm $\left(2 \mathrm{H}, \mathrm{s}, \mathrm{NH}_{2}\right)$; Anal. $\mathrm{C}_{13} \mathrm{H}_{10} \mathrm{~N}_{4} \mathrm{O}_{4} \mathrm{~S}_{2}$ (350.37): Calcd: C, 44.56; H, 2.88; N, 15.99; Found: C, 44.43; H, $2.75 ; \mathrm{N}, 15.83$.

\section{6-(4,6- Diamino-2-imino-2,5-dihydropyrimidine-5- sulfonyl)chromen-2-one (9c)}

Yield: $75 \%$; MP: $225-7{ }^{\circ} \mathrm{C}$; IR (KBr, $\left.v_{\max }, \mathrm{cm}^{-1}\right) 3415$ (br. $\left.\mathrm{NH}_{2}\right), 1705(\mathrm{C}=\mathrm{O}), 1620(\mathrm{C}=\mathrm{N}), 1563(\mathrm{C}=\mathrm{C}), 1366,1144\left(\mathrm{SO}_{2^{-}}\right.$ C), 1132, 1017 (C-O-C); ${ }^{1} \mathrm{H}$ NMR (500 MHz, DMSO- $\left.d_{6}\right): \delta 8.54$ (1H, s, H-5), $8.41(1 \mathrm{H}, \mathrm{d}, \mathrm{H}-7), 8.21(1 \mathrm{H}, \mathrm{d}, \mathrm{H}-4), 7.59(1 \mathrm{H}, \mathrm{d}, \mathrm{H}-$ 8), $6.66(1 \mathrm{H}, \mathrm{d}, \mathrm{H}-3), 4.11\left(4 \mathrm{H}, \mathrm{s}, 2 \mathrm{NH}_{2}\right), 3.04 \mathrm{ppm}\left(2 \mathrm{H}, \mathrm{s}, \mathrm{NH}_{2}\right)$; MS (m/z): $333\left[\mathrm{M}^{+}\right]$; Anal. $\mathrm{C}_{13} \mathrm{H}_{11} \mathrm{~N}_{5} \mathrm{O}_{4} \mathrm{~S}$ (333.32): Calcd: $\mathrm{C}$, 46.84; H, 3.33; N, 21.01; Found: C, 46.72; H, 3.26; N, 21.13.

\section{Cyanoacetic acid N-(6-nitro-2-oxo-2H-chromene-3- sulfonyl)hydrazide (11)}

A mixture of 6-nitro-2-oxo- $2 H$-chromene-3-sulfonyl chloride (10) (2.4 g, $0.01 \mathrm{~mol})$ and 2-cyanoacetic acid hydrazide $(1.3 \mathrm{~g}, 0.01 \mathrm{~mol})$ in absolute ethanol $(20 \mathrm{ml})$ containing triethylamine $(1 \mathrm{ml})$ was stirred for $3 \mathrm{~h}$ at room temperature. The solid that formed was filtered off, washed with water, air dried and crystallized from dry ethanol. Yield: 72\%; MP: 154-7 ${ }^{\circ} \mathrm{C}$; IR $\left(\mathrm{KBr}, v_{\max }, \mathrm{cm}^{-1}\right) 3325$ (br. NH), $2205(\mathrm{CN}), 1710(\mathrm{C}=\mathrm{O}), 1685$ $(\mathrm{C}=\mathrm{O}), 1596(\mathrm{C}=\mathrm{C}), 1386,1155\left(\mathrm{SO}_{2}-\mathrm{N}\right), 1127,1110(\mathrm{C}-\mathrm{O}-\mathrm{C}) ;{ }^{1} \mathrm{H}$ NMR (500 MHz, DMSO- $\left.d_{6}\right): \delta 9.25(1 \mathrm{H}, \mathrm{s}, \mathrm{NH}), 8.72(1 \mathrm{H}, \mathrm{s}, \mathrm{H}-$ 4), 8.56 (1H, s, H-5), 8.38 (1H, d, H-7), 7.46 (1H, d, H-8), 7.05 $(1 \mathrm{H}, \mathrm{s}, \mathrm{NH}), 4.21$ ppm $\left(2 \mathrm{H}, \mathrm{s}, \mathrm{CH}_{2}\right)$; Anal. $\mathrm{C}_{12} \mathrm{H}_{8} \mathrm{~N}_{4} \mathrm{O}_{7} \mathrm{~S}$ (352.28): 
Calcd: C, 40.91; H, 2.29; N, 15.90; Found: C, 40.83; H, 2.36; N, 16.05 .

\section{5-Amino-1 -(6-nitro-2-oxo-2H-chromene-3-sulfonyl)-1,2- dihydro-pyrazol-3-one (12)}

A solution of compound $\mathbf{1 1}(1.3 \mathrm{~g}, 0.01 \mathrm{~mol})$ in absolute ethanol $(20 \mathrm{ml})$ containing triethylamine $(1 \mathrm{ml})$ was heated under reflux for $3 \mathrm{~h}$. After cooling, the solid that formed was filtered off, washed with water, air dried and crystallized from dry ethanol. Yield: 53\%; MP: $187-9{ }^{\circ} \mathrm{C}$; IR $\left(\mathrm{KBr}, v_{\max }, \mathrm{cm}^{-1}\right) 3410\left(\mathrm{NH}_{2}\right), 3217$ $(\mathrm{NH}), 1712(\mathrm{C}=\mathrm{O}), 1676(\mathrm{C}=\mathrm{O}), 1553(\mathrm{C}=\mathrm{C}), 1373,1135\left(\mathrm{SO}_{2^{-}}\right.$ $\mathrm{N}), 1117,1055$ (C-O-C); ${ }^{1} \mathrm{H}$ NMR $\left(500 \mathrm{MHz}, \mathrm{DMSO}-d_{6}\right): \delta 8.51$ $(1 \mathrm{H}, \mathrm{s}, \mathrm{NH}), 8.52(1 \mathrm{H}, \mathrm{s}, \mathrm{H}-4), 8.31(1 \mathrm{H}, \mathrm{s}, \mathrm{H}-5), 7.99(1 \mathrm{H}, \mathrm{d}, \mathrm{H}-$ 7), $7.66(1 \mathrm{H}, \mathrm{d}, \mathrm{H}-8), 6.65(1 \mathrm{H}, \mathrm{s}, \mathrm{NH}), 4.12 \mathrm{ppm}\left(2 \mathrm{H}, \mathrm{s}, \mathrm{CH}_{2}\right) \mathrm{MS}$ $(\mathrm{m} / \mathrm{z}): 352\left[\mathrm{M}^{+}\right]$; Anal. $\mathrm{C}_{12} \mathrm{H}_{8} \mathrm{~N}_{4} \mathrm{O}_{7} \mathrm{~S}$ (352.28): Calcd: C, 40.91; H, 2.29; N, 15.90; Found: C, 40.85; H, 2.17; N, 16.03 .

\section{1-Acetyl-5-amino-4-(6-nitro-2-oxo-2H-chromene-3-sulfonyl)- 1,2-dihydropyrazol-3-one (13)}

A mixture of $\mathbf{1 0} \quad(2.4 \mathrm{~g}, \quad 0.01 \quad \mathrm{~mol})$ and 2-acetyl-2-cyanoacetohydrazide $(0.14 \mathrm{~g}, 0.01 \mathrm{~mol})$ in absolute ethanol $(20 \mathrm{ml})$ containing triethylamine $(1 \mathrm{ml})$ was stirred for $3 \mathrm{~h}$ at room temperature. The solid that formed was filtered off, washed with water; air dried and crystallized from dry ethanol. Yield: 64\%; MP: $254 \mathrm{dec} .{ }^{\circ} \mathrm{C}$; IR $\left(\mathrm{KBr}, v_{\max }, \mathrm{cm}^{-1}\right) 3422\left(\mathrm{NH}_{2}\right)$, $3172(\mathrm{NH}), 1705(\mathrm{C}=\mathrm{O}), 1657(\mathrm{C}=\mathrm{O}), 1537(\mathrm{C}=\mathrm{C}), 1365,1142$ $\left(\mathrm{SO}_{2}-\mathrm{N}\right), 1120,1035$ (C-O-C); ${ }^{1} \mathrm{H}$ NMR (500 MHz, DMSO- $\left.d_{6}\right): \delta$ $9.92(1 \mathrm{H}, \mathrm{s}, \mathrm{NH}), 8.93(1 \mathrm{H}, \mathrm{s}, \mathrm{H}-4), 8.53(1 \mathrm{H}, \mathrm{s}, \mathrm{H}-5), 8.41(1 \mathrm{H}$, d, H-7), $7.50(1 \mathrm{H}, \mathrm{d}, \mathrm{H}-8), 1.77\left(2 \mathrm{H}, \mathrm{s}, \mathrm{NH}_{2}\right) 1.35 \mathrm{ppm}(3 \mathrm{H}, \mathrm{s}$, $\mathrm{CH}_{3}$ ); $\mathrm{MS}(\mathrm{m} / \mathrm{z}): 394\left[\mathrm{M}^{+}\right]$; Anal. $\mathrm{C}_{14} \mathrm{H}_{10} \mathrm{~N}_{4} \mathrm{O}_{8} \mathrm{~S}$ (394.32): Calcd: C, 42.64; H, 2.56; N, 14.21; Found: C, 42.52; H, 2.41; N, 14.32 .

\section{6-Nitro-2-oxo-2H-chromene-3-sulfonic acid (5-0xo-4,5-} dihydro-1 $H$-pyrazol-3-yl)amide (14)

A mixture of $10(2.4 \mathrm{~g}, 0.01 \mathrm{~mol})$ and 3-amino-5pyrazolone $(0.99 \mathrm{~g}, 0.01 \mathrm{~mol})$ in absolute ethanol $(20 \mathrm{ml})$ containing triethylamine $(1 \mathrm{ml})$ was stirred for $3 \mathrm{~h}$ at room temperature, the formed precipitate was filtered off, washed with water, air dried and crystallized from dry ethanol. Yield: 81\%; MP: $279-81^{\circ} \mathrm{C}$; IR $\left(\mathrm{KBr}, v_{\max }, \mathrm{cm}^{-1}\right) 3225(\mathrm{NH}), 3156(\mathrm{NH}), 1712$ $(\mathrm{C}=\mathrm{O}), 1677(\mathrm{C}=\mathrm{O}), 1601(\mathrm{C}=\mathrm{C}), 1385,1133\left(\mathrm{SO}_{2}-\mathrm{N}\right), 1118,1072$ (C-O-C); ${ }^{1} \mathrm{H}$ NMR $\left(500 \mathrm{MHz}\right.$, DMSO- $\left.d_{6}\right): \delta 9.92(1 \mathrm{H}, \mathrm{s}, \mathrm{NH})$, $8.55(1 \mathrm{H}, \mathrm{s}, \mathrm{H}-4), 8.53(1 \mathrm{H}, \mathrm{s}, \mathrm{H}-5), 8.41(1 \mathrm{H}, \mathrm{d}, \mathrm{H}-7), 7.50(1 \mathrm{H}$, d, H-8), $4.21\left(2 \mathrm{H}, \mathrm{s}, \mathrm{CH}_{2}\right), 1.77 \mathrm{ppm}(1 \mathrm{H}, \mathrm{s}, \mathrm{NH})$; Anal. $\mathrm{C}_{12} \mathrm{H}_{8} \mathrm{~N}_{4} \mathrm{O}_{7} \mathrm{~S}$ (352.28): Calcd: C, 40.91; H, 2.29; N, 15.90; Found: C, $40.83 ; \mathrm{H}, 2.20 ; \mathrm{N}, 15.81$.

\section{Synthesis of pyrano(2,3-c)pyrazoles 15a-d}

A solution of compound $14(0.35 \mathrm{~g}, 0.001 \mathrm{~mol})$ and an appropriate arylidene malononitriles $(0.001 \mathrm{~mol})$ in dry $1,4-$ dioxane containing triethylamine $(1 \mathrm{ml})$ was refluxed for 4-6 h. After cooling, the solid that formed was filtered off, washed with water, air dried and crystallized from absolute ethanol.
6-Nitro-2-oxo-2H-chromene-3-sulfonic acid (6-amino-5-cyano4-phenylpyrano(2,3-c)pyrazol-3-yl)amide (15a)

Yield: $81 \%$; MP: $141 \mathrm{dec} .{ }^{\circ} \mathrm{C}$; IR $\left(\mathrm{KBr}, v_{\max }, \mathrm{cm}^{-1}\right) 3424$ $\left(\mathrm{NH}_{2}\right), 3212(\mathrm{NH}), 2205(\mathrm{CN}), 1717(\mathrm{C}=\mathrm{O}), 1662(\mathrm{C}=\mathrm{C}), 1386$, $1172\left(\mathrm{SO}_{2}-\mathrm{N}\right), 1122,1101$ (C-O-C); ${ }^{1} \mathrm{H}$ NMR $(500 \mathrm{MHz}, \mathrm{DMSO}-$ $\left.d_{6}\right): \delta 10.01(1 \mathrm{H}, \mathrm{s}, \mathrm{NH}), 8.71(1 \mathrm{H}, \mathrm{s}, \mathrm{H}-4), 8.31(1 \mathrm{H}, \mathrm{s}, \mathrm{H}-5), 8.20$ $(1 \mathrm{H}, \mathrm{d}, \mathrm{H}-7), 7.21-7.62(6 \mathrm{H}, \mathrm{m}, \mathrm{Ar}-\mathrm{H}), 4.57 \mathrm{ppm}\left(2 \mathrm{H}, \mathrm{s}, \mathrm{NH}_{2}\right)$; MS $(\mathrm{m} / \mathrm{z}): 504\left[\mathrm{M}^{+}\right]$; Anal. $\mathrm{C}_{22} \mathrm{H}_{12} \mathrm{~N}_{6} \mathrm{O}_{7} \mathrm{~S}$ (504.43): Calcd: C, 52.38; H, 2.40; N, 16.66; Found: C, 52.27; H, 2.31; N, 16.52.

6-Nitro-2-oxo-2H-chromene-3-sulfonic acid (6-amino-4-(4chlorophenyl)-5-cyano-pyrano(2,3-c)pyrazol-3-yl)amide (15b)

Yield: 53\%; MP: $152-4{ }^{\circ} \mathrm{C}$; IR $\left(\mathrm{KBr}, v_{\max }, \mathrm{cm}^{-1}\right) 3415$ $\left(\mathrm{NH}_{2}\right), 3165(\mathrm{NH}), 2207(\mathrm{CN}), 1715(\mathrm{C}=\mathrm{O}), 1653(\mathrm{C}=\mathrm{C}), 1375$, $1135\left(\mathrm{SO}_{2}-\mathrm{N}\right), 1117,1053(\mathrm{C}-\mathrm{O}-\mathrm{C}), 725(\mathrm{C}-\mathrm{Cl}) ; \mathrm{MS}(\mathrm{m} / \mathrm{z})$ :

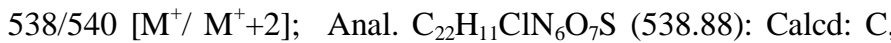
49.03; H, 2.06; N, 15.60; Found: C, 48.99; H, 2.14; N, 15.52.

6-Nitro-2-oxo-2H-chromene-3-sulfonic acid (6-amino-4-(4hydroxyphenyl)-5-cyano-pyrano(2,3-c)pyrazol -3-yl)amide (15c)

Yield: 59\%; MP: $50-2{ }^{\circ} \mathrm{C}$; IR $\left(\mathrm{KBr}, v_{\max }, \mathrm{cm}^{-1}\right) 3445$ $(\mathrm{OH}), 3365\left(\mathrm{NH}_{2}\right), 3185(\mathrm{NH}), 2212(\mathrm{CN}), 1710(\mathrm{C}=\mathrm{O}), 1623$ $(\mathrm{C}=\mathrm{C}), 1382,1145\left(\mathrm{SO}_{2}-\mathrm{N}\right), 1120,1034(\mathrm{C}-\mathrm{O}-\mathrm{C}) ;{ }^{1} \mathrm{H}$ NMR $(500$ $\left.\mathrm{MHz}, \mathrm{DMSO}-d_{6}\right): \delta 13.25(1 \mathrm{H}, \mathrm{s}, \mathrm{OH}), 9.11(1 \mathrm{H}, \mathrm{s}, \mathrm{NH}), 8.75$ $(1 \mathrm{H}, \mathrm{s}, \mathrm{H}-4), 8.40(1 \mathrm{H}, \mathrm{s}, \mathrm{H}-5), 8.17(1 \mathrm{H}, \mathrm{d}, \mathrm{H}-7), 7.06-7.70(5 \mathrm{H}$, m, Ar-H), 4.35 ppm (2H, s, $\left.\mathrm{NH}_{2}\right)$; Anal. $\mathrm{C}_{22} \mathrm{H}_{12} \mathrm{~N}_{6} \mathrm{O}_{8} \mathrm{~S}$ (520.43): Calcd: C, 50.77; H, 2.32; N, 16.15; Found: C, 50.61; H, 2.25; N, 16.05 .

6-Nitro-2-oxo-2H-chromene-3-sulfonic acid (6-amino-4-(4nitrophenyl)-5-cyano-pyrano(2,3-c)pyrazol-3-yl)amide (15d)

Yield: 55\%; MP: $75-7{ }^{\circ} \mathrm{C}$; IR $\left(\mathrm{KBr}, v_{\max }, \mathrm{cm}^{-1}\right) 3386$ $\left(\mathrm{NH}_{2}\right), 3172(\mathrm{NH}), 2195(\mathrm{CN}), 1707(\mathrm{C}=\mathrm{O}), 1596(\mathrm{C}=\mathrm{C}), 1362$, $1133\left(\mathrm{SO}_{2}-\mathrm{N}\right), 1118,1033$ (C-O-C); ${ }^{1} \mathrm{H}$ NMR $(500 \mathrm{MHz}$, DMSO$\left.d_{6}\right): \delta 8.63-7.42(8 \mathrm{H}, \mathrm{m}, \mathrm{Ar}-\mathrm{H}), 7.15(1 \mathrm{H}, \mathrm{s}, \mathrm{NH}), 2.09 \mathrm{ppm}(2 \mathrm{H}, \mathrm{s}$, $\mathrm{NH}_{2}$ ); $\mathrm{MS}(\mathrm{m} / \mathrm{z})$ : $549\left[\mathrm{M}^{+}\right]$; Anal. $\mathrm{C}_{22} \mathrm{H}_{11} \mathrm{~N}_{7} \mathrm{O}_{9} \mathrm{~S}$ (549.43): Calcd: $\mathrm{C}$, 48.09; H, 2.02; N, 17.85; Found: C, 48.13; H, 2.16; N, 17.70.

\section{2-(6-Nitro-2-oxo-2H-chromene-3-sulfonyl)malononitrile (16)}

A mixture of compound $10(2.89 \mathrm{~g}, 0.01 \mathrm{~mol})$ and malononitrile $(0.6 \mathrm{~g}, 0.01 \mathrm{~mol})$ in dry ethanol $(20 \mathrm{ml})$ containing triethylamine $(1 \mathrm{ml})$ was heated under reflux for $3 \mathrm{~h}$. The solid that formed was filtered off, washed with water, air dried and crystallized from ethanol. Yield: $86 \%$; MP: $132-4{ }^{\circ} \mathrm{C}$; $\mathrm{IR}(\mathrm{KBr}$, $\left.v_{\max }, \mathrm{cm}^{-1}\right)$ 2205, $2197(\mathrm{CN}), 1710(\mathrm{C}=\mathrm{O}), 1632(\mathrm{C}=\mathrm{C}), 1385,1175$ ( $\left.\mathrm{SO}_{2}-\mathrm{C}\right), 1110$ (C-O-C); Anal. $\mathrm{C}_{12} \mathrm{H}_{5} \mathrm{~N}_{3} \mathrm{O}_{6} \mathrm{~S}$ (319.25): Calcd: C, 45.15; H, 1.58; N, 13.16; Found: C, 45.02; H, 1.66; N, 13.09 .

\section{3-(3,5-Diamino-4H-pyrazole-4-sulfonyl)-6-nitro-chromen-2- one (17)}

To a solution of compound $\mathbf{1 6}(3.19 \mathrm{~g}, 0.01 \mathrm{~mol})$ in dry ethanol $(10 \mathrm{ml})$ containing few drops of triethylamine, hydrazine hydrate $99 \%$ ( $1 \mathrm{ml}, 0.02 \mathrm{~mol})$ was added. The reaction mixture 
was refluxed for 6-8 h. After cooling, the reaction mixture was poured onto ice-water $(50 \mathrm{ml})$, and the solid that formed was filtered off, air dried and crystallized from dry ethanol. Yield: 72\%; MP: 144 dec. ${ }^{\circ} \mathrm{C}$; IR $\left(\mathrm{KBr}, v_{\max }, \mathrm{cm}^{-1}\right) 3415$ (br. $\left.\mathrm{NH}_{2}\right), 1737$ $(\mathrm{C}=\mathrm{O}), 1618(\mathrm{C}=\mathrm{N}), 1575(\mathrm{C}=\mathrm{C}), 1375,1143\left(\mathrm{SO}_{2}-\mathrm{C}\right), 1102(\mathrm{C}-$ O-C); ${ }^{1} \mathrm{H}$ NMR (500 MHz, DMSO- $\left.d_{6}\right): \delta 8.91(1 \mathrm{H}, \mathrm{s}, \mathrm{H}-4), 8.61$ $(1 \mathrm{H}, \mathrm{s}, \mathrm{H}-5), 8.43(1 \mathrm{H}, \mathrm{d}, \mathrm{H}-7), 7.46(1 \mathrm{H}, \mathrm{d}, \mathrm{H}-8) 5.52(2 \mathrm{H}, \mathrm{s}$, $\left.\mathrm{NH}_{2}\right), 4.01(1 \mathrm{H}, \mathrm{s}, \mathrm{CH}-$ pyrazole $), 1.95 \mathrm{ppm}\left(2 \mathrm{H}, \mathrm{s}, \mathrm{NH}_{2}\right)$; $\mathrm{MS}$ $(\mathrm{m} / \mathrm{z}): 351\left[\mathrm{M}^{+}\right]$; Anal. $\mathrm{C}_{12} \mathrm{H}_{9} \mathrm{~N}_{5} \mathrm{O}_{6} \mathrm{~S}$ (351.29): Calcd: $\mathrm{C}, 41.03 ; \mathrm{H}$, 2.58; N, 19.94; Found: C, 41.19; H, 2.47; N, 19.82.

\section{Synthesis of compounds 18a-c}

A mixture of compound $\mathbf{1 6}(3.19 \mathrm{~g}, 0.01 \mathrm{~mol})$ and urea, thiourea or guanidine hydrochloride $(0.01 \mathrm{~mol})$ in dry ethanol $(10$ $\mathrm{ml})$ containing triethylamine $(0.5 \mathrm{ml})$ was refluxed for $8-10 \mathrm{~h}$. After cooling, the reaction mixture was poured onto ice-water (50 $\mathrm{ml}$ ) and the solid that formed was filtered off, air dried and crystallized from absolute ethanol.

\section{4,6-Diamino-5-(6-nitro-2-oxo-2H-chromene-3-sulfonyl)-5H- pyrimidin-2-one (18a)}

Yield: $67 \%$; MP: $176 \mathrm{dec}^{\circ} \mathrm{C}$; IR $\left(\mathrm{KBr}, v_{\max }, \mathrm{cm}^{-1}\right) 3425$, $3385\left(\mathrm{NH}_{2}\right), 1723,1695(\mathrm{C}=\mathrm{O}), 1620(\mathrm{C}=\mathrm{N}), 1587(\mathrm{C}=\mathrm{C}), 1365$, $1138\left(\mathrm{SO}_{2}-\mathrm{C}\right), 1104$ (C-O-C); ${ }^{1} \mathrm{H}$ NMR (500 MHz, DMSO- $\left.d_{6}\right): \delta$ $8.93(1 \mathrm{H}, \mathrm{s}, \mathrm{H}-4), 8.53(1 \mathrm{H}, \mathrm{s}, \mathrm{H}-5), 8.42(1 \mathrm{H}, \mathrm{d}, \mathrm{H}-7), 7.59(1 \mathrm{H}$, d, $\mathrm{H}-8), 6.57\left(1 \mathrm{H}, \mathrm{s}, \mathrm{CH}\right.$ pyrimidine), $3.02\left(2 \mathrm{H}, \mathrm{s}, \mathrm{NH}_{2}\right), 1.78 \mathrm{ppm}$ $\left(2 \mathrm{H}, \mathrm{s}, \mathrm{NH}_{2}\right)$; $\mathrm{MS}(\mathrm{m} / \mathrm{z}): 379\left[\mathrm{M}^{+}\right]$; Anal. $\mathrm{C}_{13} \mathrm{H}_{9} \mathrm{~N}_{5} \mathrm{O}_{7} \mathrm{~S}$ (379.30): Calcd: C, 41.16; H, 2.39; N, 18.46; Found: C, 41.07; H, 2.26; N, 18.35 .

\section{3-(4,6-Diamino-2-thioxo-2,5-dihydro-pyrimidine-5-sulfonyl)-6- nitro-chromen-2-one (18b)}

Yield: $56 \%$; MP: $119-21^{\circ} \mathrm{C}$; IR $\left(\mathrm{KBr}, v_{\max }, \mathrm{cm}^{-1}\right) 3427$ (br. $\left.\mathrm{NH}_{2}\right), 1725(\mathrm{C}=\mathrm{O}), 1618(\mathrm{C}=\mathrm{N}), 1555(\mathrm{C}=\mathrm{C}), 1240(\mathrm{C}=\mathrm{S})$, 1366, 1147 ( $\left.\mathrm{SO}_{2}-\mathrm{C}\right), 1113$ (C-O-C); ${ }^{1} \mathrm{H}$ NMR (500 MHz, DMSO$\left.d_{6}\right): \delta 8.87(1 \mathrm{H}, \mathrm{s}, \mathrm{H}-4), 8.42(1 \mathrm{H}, \mathrm{s}, \mathrm{H}-5), 8.37$ (1H, d, H-7), 7.57 $(1 \mathrm{H}, \mathrm{d}, \mathrm{H}-8), 6.40\left(1 \mathrm{H}, \mathrm{s}, \mathrm{CH}\right.$ pyrimidine), $3.13\left(2 \mathrm{H}, \mathrm{s}, \mathrm{NH}_{2}\right), 1.91$ ppm (2H, s, $\mathrm{NH}_{2}$ ); Anal. $\mathrm{C}_{13} \mathrm{H}_{9} \mathrm{~N}_{5} \mathrm{O}_{6} \mathrm{~S}_{2}$ (395.37): Calcd: C, 39.49; H, 2.29; N, 17.71; Found: C, 39.37; H, 2.21; N, 17.62 .

\section{3-(4,6-Diamino-2-imino-2,5-dihydro-pyrimidine-5-sulfonyl)-6- nitro-chromen-2-one (18c)}

Yield: 51\%; MP: $143-5^{\circ} \mathrm{C}$; IR ( $\left.\mathrm{KBr}, v_{\max }, \mathrm{cm}^{-1}\right) 3415$ (br. $\left.\mathrm{NH}_{2}\right), 1720(\mathrm{C}=\mathrm{O}), 1620(\mathrm{C}=\mathrm{N}), 1556(\mathrm{C}=\mathrm{C}), 1368,1157\left(\mathrm{SO}_{2^{-}}\right.$ C), 1107 (C-O-C); MS (m/z): $378\left[\mathrm{M}^{+}\right]$; Anal. $\mathrm{C}_{13} \mathrm{H}_{10} \mathrm{~N}_{6} \mathrm{O}_{6} \mathrm{~S}$ (378.32): Calcd: C, 41.27; H, 2.66; N, 22.21; Found: C, 41.19; H, 2.52; N, 22.11.

\section{$N$-(Chlorosulfonyl)- $N$-(2-oxo-2H-chromen-6-yl)formamidine} (21)

To a stirred solution of compound $20(0.94 \mathrm{~g}, 0.005 \mathrm{~mol})$ in dry benzene $(10 \mathrm{ml})$ was added a solution of chlorosulfonyl isocyanate $(0.87 \mathrm{ml}, 0.01 \mathrm{~mol})$ in dry benzene $(5 \mathrm{ml})$ at $0-5{ }^{\circ} \mathrm{C}$ during $20 \mathrm{~min}$, and the stirring was continued for additional $1 \mathrm{~h}$ at the same temperature. The reaction mixture allowed attaining at room temperature for additional $30 \mathrm{~min}$. The reaction mixture was cooled at refrigerator overnight and the solid that formed was filtered off, air dried and crystallized from dry benzene. Yield: 53 \%; MP: 224-6 ${ }^{\circ} \mathrm{C}$; IR $\left(\mathrm{KBr}, v_{\max }, \mathrm{cm}^{-1}\right) 3255(\mathrm{NH}), 1733(\mathrm{C}=\mathrm{O})$, $1618(\mathrm{C}=\mathrm{N}), 1563(\mathrm{C}=\mathrm{C}), 1385,1154\left(\mathrm{SO}_{2}-\mathrm{N}\right) ; \mathrm{MS}(\mathrm{m} / \mathrm{z}): 286 / 288$ $\left[\mathrm{M}^{+} / \mathrm{M}^{+}+2\right]$; Anal. $\mathrm{C}_{10} \mathrm{H}_{7} \mathrm{ClN}_{2} \mathrm{O}_{4} \mathrm{~S}$ (286.69): Calcd: $\mathrm{C}, 41.89 ; \mathrm{H}$, 2.46; N, 9.77; Found: C, 41.74; H, 2.35; N, 9.61.

\section{1-( $N$-sulfonylchloride)-3-(2-oxo-2H-chromen-6-yl) urea (22)}

To a stirred solution of $\mathbf{1 9}(1.6 \mathrm{~g}, 0.01 \mathrm{~mol})$ in dry benzene $(10 \mathrm{ml})$ was added a solution of chlorosulfonyl isocyanate $(0.87 \mathrm{ml}, 0.01 \mathrm{~mol})$ in dry benzene $(5 \mathrm{ml})$ at $0-5^{\circ} \mathrm{C}$ during $20 \mathrm{~min}$, and the stirring was continued for additional $1 \mathrm{~h}$ at the same temperature. The reaction mixture allowed attaining at room temperature for additional $30 \mathrm{~min}$. The solid that formed was filtered off; air dried and was used without subsequent cleaning. Yield: $51 \%$; MP: $139-41{ }^{\circ} \mathrm{C}$; IR $\left(\mathrm{KBr}, v_{\max }, \mathrm{cm}^{-1}\right) 3225,3165$ $(\mathrm{NH}), \quad 1735,1664(\mathrm{C}=\mathrm{O}), 1603(\mathrm{C}=\mathrm{C}), 1345,1163\left(\mathrm{SO}_{2}\right), 1109$ $(\mathrm{C}-\mathrm{O}-\mathrm{C}), 761(\mathrm{C}-\mathrm{Cl}) ;{ }^{1} \mathrm{H}$ NMR $\left(500 \mathrm{MHz}, \mathrm{DMSO}-d_{6}\right): \delta 8.95(1 \mathrm{H}$, s, NH), $8.32(1 \mathrm{H}, \mathrm{s}, \mathrm{H}-5), 8.03(1 \mathrm{H}, \mathrm{d}, \mathrm{H}-7), 7.91(1 \mathrm{H}, \mathrm{d}, \mathrm{H}-4)$, $7.52(1 \mathrm{H}, \mathrm{d}, \mathrm{H}-8), 7.17(1 \mathrm{H}, \mathrm{s}, \mathrm{NH}), 6.52 \mathrm{ppm}(1 \mathrm{H}, \mathrm{d}, \mathrm{H}-3)$; MS $(\mathrm{m} / \mathrm{z})$ : 302/304 [ $\left.\mathrm{M}^{+} / \mathrm{M}^{+}+2\right]$; Anal. $\mathrm{C}_{10} \mathrm{H}_{7} \mathrm{ClN}_{2} \mathrm{O}_{5} \mathrm{~S}$ (302.69): Calcd: C, 39.68; H, 2.33; N, 9.25; Found: C, 39.55; H, 2.28; N, 9.18.

\section{2,7-Dioxo-pyrano(3,2-f)-1,3,4-benzothiazine-5,5-dioxide (23)}

To a freshly prepared solution of compound $22(0.005$ mol) in dry benzene $(10 \mathrm{ml})$ aluminum chloride $(0.66 \mathrm{~g}, 0.005$ mol) was added at once under stirring at room temperature and then the reaction mixture was refluxed for $30 \mathrm{~min}$. After cooling, the reaction mixture was poured onto ice-water $(20 \mathrm{ml})$, and the solid that formed was filtered off, air dried and crystallized from absolute ethanol. Yield: $30 \%$; MP: $123-5^{\circ} \mathrm{C}$; IR $\left(\mathrm{KBr}, v_{\max }, \mathrm{cm}^{-1}\right)$ $3365(\mathrm{NH}), 1737,1655(\mathrm{C}=\mathrm{O}), 1620(\mathrm{C}=\mathrm{C}), 1359,1171\left(\mathrm{SO}_{2}\right)$, 1111 (C-O-C); ${ }^{1} \mathrm{H}$ NMR (500 MHz, DMSO- $\left.d_{6}\right): \delta 8.33(1 \mathrm{H}, \mathrm{d}, \mathrm{H}-$ 7), $8.01(1 \mathrm{H}, \mathrm{d}, \mathrm{H}-4), 7.62(1 \mathrm{H}, \mathrm{d}, \mathrm{H}-8), 6.46(1 \mathrm{H}, \mathrm{d}, \mathrm{H}-3), 4.23$ ppm $(2 \mathrm{H}, \mathrm{s}, 2 \mathrm{NH}) ; \mathrm{MS}(\mathrm{m} / \mathrm{z}): 266\left[\mathrm{M}^{+}\right]$; Anal. $\mathrm{C}_{10} \mathrm{H}_{6} \mathrm{~N}_{2} \mathrm{O}_{5} \mathrm{~S}$ (266.23): Calcd: C, 45.11; H, 2.27; N, 10.52; Found: C, 45.02; H, $2.20 ; \mathrm{N}, 10.43$.

\section{Synthesis of benzenesulfonamides $24 \mathrm{a}$ and $24 \mathrm{~b}$}

A mixture of compound $19(0.19 \mathrm{~g}, 0.0005 \mathrm{~mol})$ and 4bromobenzenesulfonyl chloride or 4-chlorobenzenesulfonyl chloride $(0.0005 \mathrm{~mol})$ in dry 1,4-dioxane $(10 \mathrm{ml})$ containing few drops of triethylamine was heated under reflux for 8-10 h. After cooling, the reaction mixture was poured onto cold water $(20 \mathrm{ml})$. The solid that formed was filtered off, air dried and crystallized from 1,4-dioxane.

\section{4-Bromo- $N$-(2-oxo-2H-chromen-6-yl)benzenesulfonamide (24a)}

Yield: $85 \%$; MP: $160-2{ }^{\circ} \mathrm{C}$; IR $\left(\mathrm{KBr}, v_{\max }, \mathrm{cm}^{-1}\right) 3210$ $(\mathrm{NH}), 1722(\mathrm{C}=\mathrm{O}), 1605(\mathrm{C}=\mathrm{C}), 1364,1138\left(\mathrm{SO}_{2}-\mathrm{N}\right), 1101(\mathrm{C}-\mathrm{O}-$ C), 780 (C-Br); $\mathrm{MS} \quad(\mathrm{m} / \mathrm{z}): 379 / 381 \quad\left[\mathrm{M}^{+} / \mathrm{M}^{+}+2\right]$; Anal. 
$\mathrm{C}_{15} \mathrm{H}_{10} \mathrm{BrNO}_{4} \mathrm{~S}$ (380.21): Calcd: C, 47.38; H, 2.65; N, 3.68; Found: C, $47.30 ; \mathrm{H}, 2.55 ; \mathrm{N}, 3.59$.

\section{4-Chloro- $\mathrm{N}$-(2-oxo-2H-chromen-6-yl)benzenesulfonamide} (24b)

Yield: 87\%; MP: $113-5{ }^{\circ} \mathrm{C}$; IR $\left(\mathrm{KBr}, v_{\max }, \mathrm{cm}^{-1}\right) 3185$ $(\mathrm{NH}), 1710(\mathrm{C}=\mathrm{O}), 1635(\mathrm{C}=\mathrm{C}), 1357,1135\left(\mathrm{SO}_{2}-\mathrm{N}\right), 1112(\mathrm{C}-\mathrm{O}-$ C), $752(\mathrm{C}-\mathrm{Cl})$; $\mathrm{MS}(\mathrm{m} / \mathrm{z}): 335 / 337 \quad\left[\mathrm{M}^{+} / \mathrm{M}^{+}+2\right]$; Anal. $\mathrm{C}_{15} \mathrm{H}_{10} \mathrm{ClNO}_{4} \mathrm{~S}$ (335.76): Calcd: C, 53.66; H, 3.00; N, 4.17; Found: C, 53.56; H, 2.94; N, 4.09.

\section{Synthesis of $\mathrm{N}$-chlorosulfonyl ureas $25 \mathrm{a}$ and $25 \mathrm{~b}$}

To a stirred solution of compound $\mathbf{2 4 a}$ or $\mathbf{2 4 b}(0.01 \mathrm{~mol})$ in dry benzene $(10 \mathrm{ml})$ was added a solution of chlorosulfonyl isocyanate $(0.87 \mathrm{ml}, 0.01 \mathrm{~mol})$ in dry benzene $(5 \mathrm{ml})$ at $0-5{ }^{\circ} \mathrm{C}$ during $20 \mathrm{~min}$, and the stirring was continued for additional $1 \mathrm{~h}$ at the same temperature. The reaction mixture allowed attaining at room temperature for additional $30 \mathrm{~min}$. The solid that formed was filtered off; air dried and was used without subsequent cleaning.

\section{$N$-(4-Bromobenzene sulfonyl)- $N$-(2-oxo-2H-chromen-6-yl)- $N-$ chlorosulfonyl urea (25a)}

Yield: $42 \%$; MP: $160-2^{\circ} \mathrm{C}$; IR $\left(\mathrm{KBr}, v_{\max }, \mathrm{cm}^{-1}\right) 3185$ $(\mathrm{NH}), 1731,1688(\mathrm{C}=\mathrm{O}), 1608(\mathrm{C}=\mathrm{C}), 1375,1153\left(\mathrm{SO}_{2}-\mathrm{N}\right), 1115$ (C-O-C), $778(\mathrm{C}-\mathrm{Br}) ;{ }^{1} \mathrm{H}$ NMR (500 MHz, DMSO-d $)$ ): $\delta 9.15(1 \mathrm{H}$, s, NH), 8.33-7.27 (8H, m, Ar-H), 6.61 ppm (1H, d, H-3); Anal. $\mathrm{C}_{16} \mathrm{H}_{10} \mathrm{BrClN}_{2} \mathrm{O}_{7} \mathrm{~S}_{2}$ (521.75): Calcd: C, 36.83; H, 1.93; N, 5.37; Found: C, 36.75; H, 1.82; N, 5.25.

\section{$N$-(4-Chlorobenzene sulfonyl)- $N$-(2-oxo-2H-chromen-6-yl)- $N-$ chlorosulfonyl urea (25b)}

Yield: 45\%; MP: $157-9{ }^{\circ} \mathrm{C}$; IR $\left(\mathrm{KBr}, v_{\max }, \mathrm{cm}^{-1}\right) 3212$ $(\mathrm{NH}), 1735,1657(\mathrm{C}=\mathrm{O}), 1575(\mathrm{C}=\mathrm{C}), 1368,1145\left(\mathrm{SO}_{2}-\mathrm{N}\right), 1122$ (C-O-C), 775 (C-Cl); ${ }^{1} \mathrm{H}$ NMR (500 MHz, DMSO-d6): $\delta$ 8.55-7.21 $(8 \mathrm{H}, \mathrm{m}, \mathrm{Ar}-\mathrm{H}), 6.65(1 \mathrm{H}, \mathrm{d}, \mathrm{H}-3), 5.25 \mathrm{ppm}(1 \mathrm{H}, \mathrm{s}, \mathrm{NH})$; Anal. $\mathrm{C}_{16} \mathrm{H}_{10} \mathrm{Cl}_{2} \mathrm{~N}_{2} \mathrm{O}_{7} \mathrm{~S}_{2}$ (477.30): Calcd: C, 40.26; H, 2.11; N, 5.87; Found: C, 40.17; H, 2.05; N, 5.77.

\section{Synthesis of pyrano(3,2-g) $[1,3,4]$ benzothiazine-9,9-dioxides 26a} and $26 \mathrm{~b}$

To a freshly prepared solution of compound $\mathbf{2 5 a}$ or $\mathbf{2 5} \mathbf{b}$ $(0.005 \mathrm{~mol})$ in dry benzene $(10 \mathrm{ml})$ aluminum chloride $(0.66 \mathrm{~g}$, $0.005 \mathrm{~mol}$ ) was added at once under stirring at room temperature and then the reaction mixture was refluxed for $30 \mathrm{~min}$. After cooling, the reaction mixture was poured onto ice-water $(20 \mathrm{ml})$, and the solid that formed was filtered off, air dried and crystallized from absolute ethanol.

\section{2,7-Dioxo-6-(4-bromobenzenesulfonyl)-pyrano(3,2- g) $[1,3,4]$ benzothiazine-9,9-dioxide (26a)}

Yield: $31 \%$; MP: $172-74{ }^{\circ} \mathrm{C}$; IR $\left(\mathrm{KBr}, v_{\max }, \mathrm{cm}^{-1}\right) 3215$ $(\mathrm{NH}), 1732,1675(\mathrm{C}=\mathrm{O}), 1585(\mathrm{C}=\mathrm{C}), 1372,1145\left(\mathrm{SO}_{2}-\mathrm{N}\right), 1105$ (C-O-C), 775 (C-Br); ${ }^{1} \mathrm{H}$ NMR (500 MHz, DMSO- $\left.d_{6}\right): \delta 8.45-7.17$ (8H, m, Ar-H), 6.60 ppm (1H, d, H-3); MS (m/z): 484/486 [M+/
$\mathrm{M}^{+}+2$ ]; Anal. $\mathrm{C}_{16} \mathrm{H}_{9} \mathrm{BrN}_{2} \mathrm{O}_{7} \mathrm{~S}_{2}$ (485.29): Calcd: C, 39.60; $\mathrm{H}, 1.87$; N, 5.77; Found: C, 39.51; H, 1.73; N, 5.66.

\section{2,7-Dioxo-6-(4-chlorobenzenesulfonyl)-pyrano(3,2- g) $[1,3,4]$ benzothiazine-9,9-dioxide (26b)}

Yield: $32 \%$; MP: $185-7{ }^{\circ} \mathrm{C}$; IR $\left(\mathrm{KBr}, v_{\max }, \mathrm{cm}^{-1}\right) 3302$ $(\mathrm{NH}), 1733,1683(\mathrm{C}=\mathrm{O}), 1567(\mathrm{C}=\mathrm{C}), 1355,1135\left(\mathrm{SO}_{2}-\mathrm{N}\right), 1102$ (C-O-C), $777(\mathrm{C}-\mathrm{Cl}) ;{ }^{1} \mathrm{H}$ NMR (500 MHz, DMSO-d $): \delta 8.83(1 \mathrm{H}$, s, NH), 8.54-7.47 (7H, m, Ar-H), 6.45 ppm (1H, d, H-3); MS $(\mathrm{m} / \mathrm{z})$ : 440/442 [ $\left.\mathrm{M}^{+} / \mathrm{M}^{+}+2\right]$; Anal. $\mathrm{C}_{16} \mathrm{H}_{9} \mathrm{ClN}_{2} \mathrm{O}_{7} \mathrm{~S}_{2}$ (440.83): Calcd: C, 43.59; H, 2.06; N, 6.35; Found: C, 43.47; H, 2.13; N, 6.22.

\section{Biological assay \\ Cell line propagation}

Hepatocellular carcinoma (HepG2) was purchased from the holding company for biological products and vaccines (VACSERA, Agouza Giza Egypt). Cells were routinely propagated and maintained in RPMI-1640 medium with Lglutamine (Sigma-Aldrich, St Louis, Missouri, USA) and supplemented with fetal calf serum (Sigma-Aldrich, St Louis, Missouri, USA) $10 \%$ for growth and $2 \%$ for maintenance medium and $1 \%$ antibiotic mixture $\left(20 \mathrm{U} \mathrm{ml}^{-1}\right.$ of penicillin $\mathrm{G}$ sodium and $20 \mathrm{mg} \mathrm{ml}^{-1}$ streptomycin sulfate, Gibco ${ }^{\mathrm{TM}}$, Thermo Fisher Scientific, Van Allen way carlsbad, CA 92008, USA). Media were changed every 3 days. HepG2 cells were propagated at approximately $80 \%$ confluence then trypsinized.

\section{MTT cytotoxicity assay}

Cytotoxicity against HepG2 cells was assessed by MTT [3- (4, 5-dimethylthiazol-2-yl)-2, 5-diphenyltetrazolium bromide] (Bio Basic Canada Inc., Canada) assay (Mosmann 1983). This reaction depends on the mitochondrial reduction of yellow MTT into purple formazan. All the preceding steps were carried out in sterile laminar air flow cabinet Biosafety class II level (Baker, SG403INT; Sanford, ME, USA). Briefly, cells were seeded in 96well microplates ( 3 X $10^{3}$ cells/well) in $100 \mu 1$ RPMI-1640 culture medium and incubated at $37{ }^{\circ} \mathrm{C}$ and $5 \% \mathrm{CO}_{2}$ overnight. The cells were treated and re-incubated for 24 and $48 \mathrm{~h}$. MTT $\left(0.5 \mathrm{mg} \mathrm{ml}^{-1}\right)$ solution was added to each well $(100 \mu \mathrm{l})$, and the cells were incubated over night until the purple formazan crystals appeared. The medium was discarded; $100 \mu \mathrm{l}$ of DMSO was added to dissolve the crystals. The optical density (OD) of solubilized formazan was measured at $570 \mathrm{~nm}$ using an automatic microplate reader (Bio-Rad Laboratories, model 3350, USA). Dimethyl sulfoxide (DMSO) was the vehicle used for dissolution of testing compound and its final concentration on the cells was less than $0.2 \%$.Results are expressed as percent of control.

\section{Reverse transcription-polymerase chain reaction (RT-PCR) and Real-time Quantitative PCR (q-PCR).}

Total RNA was isolated using RNeasy mini Kit (Qiagen, Valencia, CA USA). RNA was reverse transcribed into cDNA using RevertAid First Strand cDNA Synthesis Kit (Thermo Fisher Scientific, Van Allen way carlsbad, CA 92008, USA) according to 
manufacturer. For quantitative real-time PCR, amplification mixtures were prepared using KAPA SYBR_FAST q PCR master mix (KapaBiosystem, Inc., 200 Ballardvale Street Suite 350 Wilmington, USA). Gyceraldehyde-3-phosphate dehydrogenase (GAPDH) (Shao et al, 2014) was used as an internal reference gene to normalize the expression of following genes, namely CD105 (Zemelet al, 2009), CD44 (Biddle et al, 2013), and IGF (Chen et al, 2012). The results were expressed as the ratio of reference gene mRNA to target gene mRNA using $2^{-\Delta \Delta \mathrm{Ct}}$ method.

\section{Transwell $^{\circledR}$ migration assay}

Migration assay was performed in a 24-well transwell ${ }^{\circledR}$ (Sigma-Aldrich, St Louis, Missouri, USA) using polycarbonate membranes with $8-\mu \mathrm{m}$ pores (Corning ${ }^{\circledR}$ Costar, Cambridge, UK). HepG2 cells were serum-starved by incubating the cells in serumfree media and kept in a $37{ }^{\circ} \mathrm{C}$ and $5 \% \mathrm{CO}_{2}$ incubator for $24 \mathrm{~h}$. At a density of $6 \times 105$ cells $\mathrm{ml}^{-1}$ in $100 \mu \mathrm{l}$ of serum free medium, HepG2 cells were placed in the upper chamber of the transwell assembly. The lower chamber contained $650 \mu \mathrm{l}$ of RPMI medium. After incubation at $37{ }^{\circ} \mathrm{C}$ and $5 \% \mathrm{CO}_{2}$ for $24 \mathrm{~h}$, the upper surface of the membrane was scraped gently to remove non-migrating cells and washed with phosphate-buffered saline. The membrane was then fixed in $4 \%$ paraformaldehyde for $15 \mathrm{~min}$, and stained with hematoxylin and eosin. The cells were then imaged in five fields for each membrane and counted using image $\mathrm{J}$.

\section{MMP-2 activity}

MMP-2 activity was measured by RayBio Human MMP-

2 ELISA Kit (RayBiotech, Inc., 3607 Parkway Lane suite 200, Norcross, GA 30092, USA), which employs an antibody specific for human MMP-2 coated on a 96-well plate, according to manufacturer. Briefly, Standards and samples are pipetted into the wells and MMP-2 present in a sample is bound to the wells by the immobilized antibody. The wells are washed and biotinylated antihuman MMP-2 antibody is added. After washing away unbound biotinylated antibody, HRP-conjugated streptavidin is pipetted to the wells. The wells are again washed, a TMB substrate solution is added to the wells and color develops in proportion to the amount of MMP-2 bound. The Stop Solution changes the color from blue to yellow, and the intensity of the color is measured at $450 \mathrm{~nm}$.

\section{Molecular docking}

Molecular docking study of coumarin derivatives 4, 5, 8, 12, 13 and 14 were performed by Molecular Operating Environment (MOE) 2008.10 (http://www.chemcomp.com). The PDB code $1 \mathrm{HOV}$ was downloaded from protein data bank (http://www. rcsb. org/pdb) (Feng et al, 2002) and prepared for docking process. The co-crystalline ligands were re-docked in the active pockets to validate the docking protocol.

The structure of the target compounds was drawn in ChemDraw Ultra 10.0 (ChemOffice package) and the energy were minimized using the MMFF94x force field until an RMSD (Rootmean-square deviation) of atomic position gradient of (0.01) Kcal mol $^{-1} \AA^{-1}$. MMFF94x was reported as the efficient force field for minimizing ligand-protein complexes (Kaminski and Jorgensen 1996)

The docking Algorithm was done by MOE-DOCK default which uses flexible, a rigid technique for posing the molecule inside the cavity. All rotatable bonds of ligands are allowed to undergo free rotation to explore the conformational space inside the rigid receptor binding site.

\section{RESULTS AND DISCUSSIONS}

\section{Chemistry}

Schemes 1, 2 and 3 illustrate the reaction routes for the synthesis of the title compounds. Reaction of 2-oxo- $2 \mathrm{H}$ chromene-6-sulfonyl chloride (1) with 2-cyanoacetic acid hydrazide in the presence of few drops of triethylamine under stirring at room temperature led to the formation of $N^{\prime}$-(2cyanoacetyl)-2-oxo-2 $\mathrm{H}$-chromene-6-sulfonohydrazide (2). It's ${ }^{1} \mathrm{H}$ NMR spectrum revealed singlet signals at 9.52 and $7.15 \mathrm{ppm}$ for $\mathrm{NH}$, and $3.15 \mathrm{ppm}$ for $\mathrm{CH}_{2}$ besides the other signals which located at their position. The IR spectrum of 2 showed absorption bands at $2205 \mathrm{~cm}^{-1}$ for $\mathrm{CN}$ besides the $\mathrm{CO}$ group at 1705 and $1654 \mathrm{~cm}^{-1}$. Intracyclization of the later compound under heating in absolute ethanol containing few drops of triethylamine yielded the aminopyrazolone derivative (3) (Scheme 1). It's IR spectrum showed the absence of $\mathrm{CN}$ group and showed new absorption bands at $\mathrm{cm}^{-1} 3410$ and 3325 characteristic for $\mathrm{NH}_{2}$.

On the other hand, reaction of 1 with 2-acetyl-2cyanoacetohydrazide in absolute ethanol containing few drops of triethylamine yielded, the cyclized 1-acetyl-5-amino-1,2-dihydropyrazol-3-one derivative (4) (Scheme 1). The IR spectrum of 4 showed the absence of $\mathrm{CN}$ group and showed new characteristic absorption bands at $3462,3346 \mathrm{~cm}^{-1}$ for $\mathrm{NH}_{2}$ beside the absorption band at 3165 for $\mathrm{NH}$.

On the other hand, the base catalyzed reaction of $\mathbf{1}$ with 3-amino-5-pyrazolinone in dry 1,4-dioxane afforded 2-oxo- $2 \mathrm{H}$ chromene-6-sulfonic acid(5-oxo-4,5-dihydro- $1 H$-pyrazol-3yl)amide (5) (Scheme 1). The reaction of the later compound with some arylidene malononitriles, namely benzylidene malononitrile, 4-chloro, 4-hydroxy, 2-nitrobenzylidene malononitriles in refluxing 1,4-dioxane containing triethylamine led to the formation of the fused system pyrano(2,3-c)pyrazole derivatives 6a-d (Scheme 1).

Moreover, base catalyzed reaction of $\mathbf{1}$ with malononitrile in dry ethanol afforded 2-(2-oxo-2H-chromene-6sulfonyl)malononitrile (7) (Scheme 1). Cyclization of 7 via its reaction with hydrazine hydrate, urea, thiourea and/or guanidine hydrochloride in dry ethanol and in the presence of triethylamine led to the formation of the corresponding pyrazole $\mathbf{8}$ and pyrimidine derivatives 9a-c, respectively (Scheme 1). In the next bid of the synthesis of new coumarin derivatives, we introduced nitro group at 6-position of coumarin for deactivation the benzene ring of coumarin moiety in order to enhance the electrons density of pyrone ring at 3-position in order to prepare the 6-nitro-2-oxo2H-chromene-3-sulfonyl chloride (10) (Abd El-Hafez et al., 1994). 


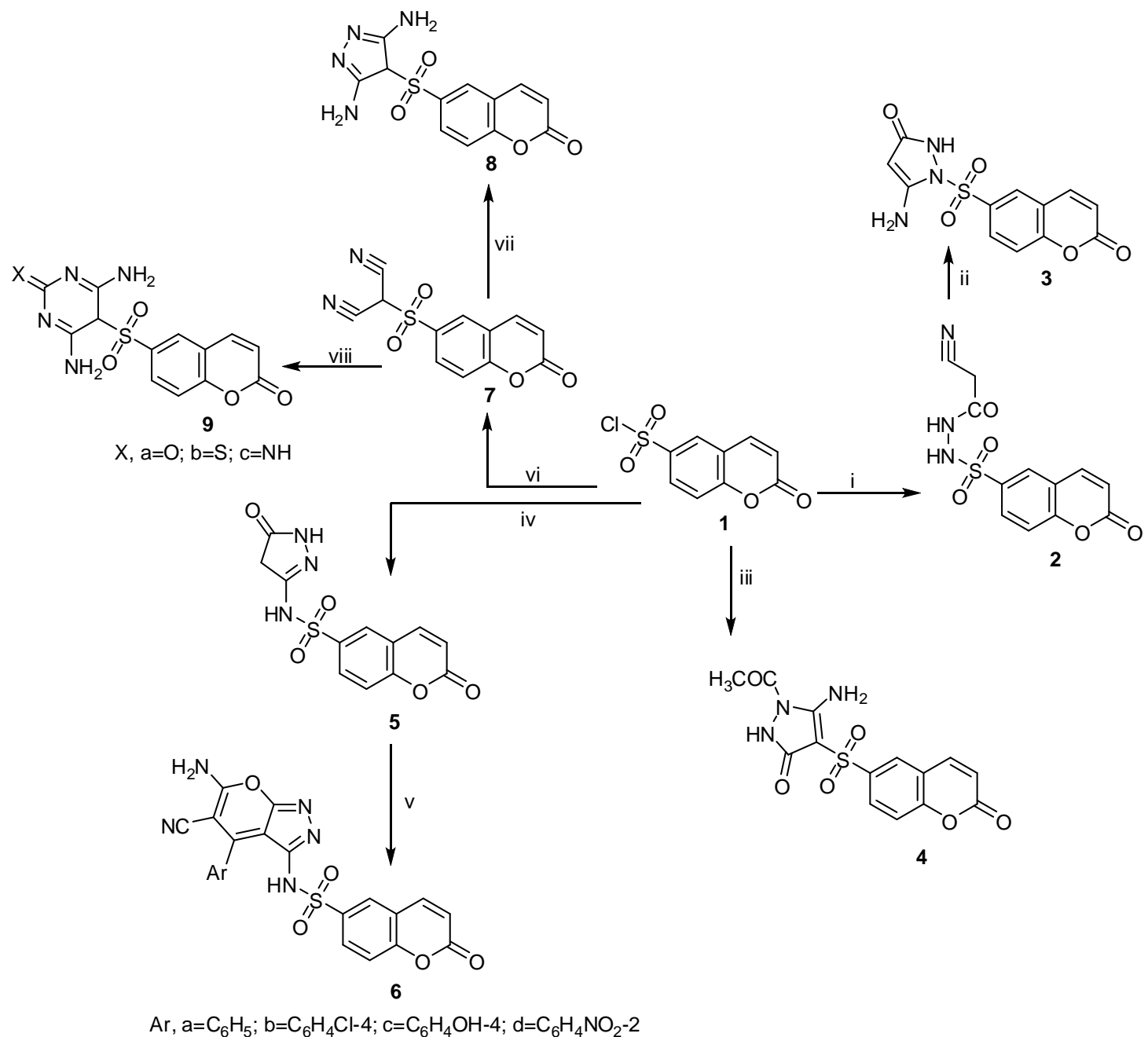

Scheme 1: reagents and conditions: (i) $\mathrm{CNCH}_{2} \mathrm{CONHNH}_{2}$; EtOH; TEA; r.t., (ii) EtOH; TEA; reflux, (iii) $\mathrm{CNCH}_{2} \mathrm{CONHNHCOCH}_{3}$; EtOH; TEA; reflux, (iv) 3 amino-5-pyrazolone; EtOH; TEA; r.t., (v) $\mathrm{Ar}-\mathrm{CH}=\mathrm{C}(\mathrm{CN})_{2}$; EtOH; TEA; reflux, (vi) $\mathrm{CH}_{2}(\mathrm{CN})_{2}$; EtOH; TEA; reflux, (vii) $\mathrm{NH}_{2} \mathrm{NH}_{2} . \mathrm{H}_{2} \mathrm{O}$; EtOH; TEA, (viii) $\mathrm{NH}_{2} \mathrm{CXNH}_{2} ; \mathrm{EtOH} ; \mathrm{TEA}$.

Similarly reaction of $\mathbf{1 0}$ with 2-cyanoacetic acid hydrazide in the presence of few drops of triethylamine under stirring at room temperature led to the formation of $\mathrm{N}$-(6-nitro-2oxo-2H-chromene-3-sulfonyl)hydrazide (11). Cyclocondensation of the later compound under heating in absolute ethanol containing few drops of triethylamine led to the formation of 5-amino-1,2dihydro-pyrazol-3-one derivative (12) (Scheme 2).

Furthermore, cyclocondensation of $\mathbf{1 0}$ with 2-acetyl-2cyanoaceto-hydrazide in the presence of few drops of triethylamine afforded 1-acetyl-5-amino-4-(6-nitro-2-oxo- $2 \mathrm{H}$ chromene-3-sulfonyl)-1,2-dihydro-pyrazol-3-one (13) (Scheme 2). While, reaction of compound $\mathbf{1 0}$ with 3-amino-5-pyrazolinone in the presence of triethylamine gave 6-nitro-2-oxo- $2 \mathrm{H}$-chromene-3sulfonic acid(5-oxo-4,5-dihydro- $1 H$-pyrazol-3-yl)amide (Scheme 2). Cyclization of $\mathbf{1 4}$ with some arylidene malononitriles, namely benzylidene malononitrile, 4-chloro, 4hydroxy, 2-nitrobenzylidene malononitriles in refluxing 1,4dioxane containing triethylamine led to the formation of the fused system, pyrano(2,3-c)pyrazole derivatives 15a-d (Scheme 2).
Moreover, reaction of compound $\mathbf{1 0}$ with malononitrile under reflux in dry ethanol containing few drops of triethylamine afforded 2-(6-nitro-2-oxo-2H-chromene-3-sulfonyl)malononitrile (16) (Scheme 2). Hetero-cyclization of the later compound via its reaction with hydrazine hydrate, urea, thiourea and/or guanidine hydrochloride in dry ethanol in the presence of triethylamine led to the formation of the corresponding pyrazole $\mathbf{1 7}$ and pyrimidine derivatives 18a-c, respectively (Scheme 2).

6-Aminocoumarin (19) was obtained via the reduction of 6-nitrocoumarin using stannous chloride in the presence of tin granules, which under formylation with formic acid yielded the corresponding $\mathrm{N}$-(2-oxo-2H-chromen-6-yl)formamide (Morgan and Micklethwait 1904).

The behavior of chlorosulfonyl isocyanate (CSI) towards aldehyde under stirring in benzene at $0-5{ }^{\circ} \mathrm{C}$ results in the formation of $\left(-\mathrm{HC}=\mathrm{NSO}_{2} \mathrm{Cl}\right)$, while, nucleophilic addition reaction of CSI with amine under the previous condition results in the formation of $N$-chlorosulfonyl derivative $\left(-\mathrm{CONHSO}_{2} \mathrm{Cl}\right)(\mathrm{Dahr}$ and Murthy 1986). 


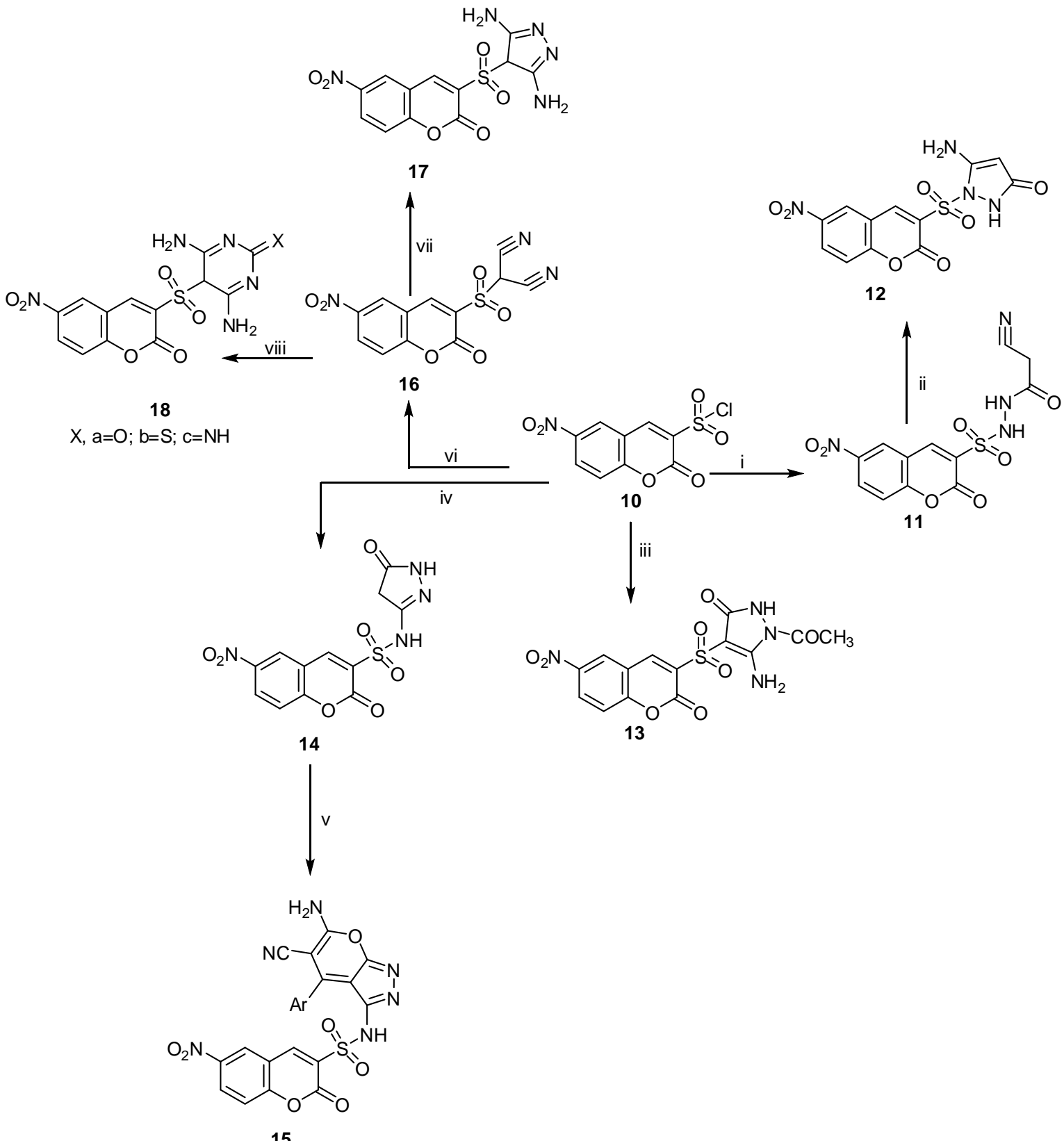

Ar, $a=\mathrm{C}_{6} \mathrm{H}_{5} ; b=\mathrm{C}_{6} \mathrm{H}_{4} \mathrm{Cl}-4 ; \mathrm{c}=\mathrm{C}_{6} \mathrm{H}_{4} \mathrm{OH}-4 ; d=\mathrm{C}_{6} \mathrm{H}_{4} \mathrm{NO}_{2}-2$

Scheme 2: reagents and conditions: (i) $\mathrm{CNCH}_{2} \mathrm{CONHNH}_{2}$; EtOH; TEA; r.t., (ii) EtOH; TEA; reflux, (iii) $\mathrm{CNCH}_{2} \mathrm{CONHNHCOCH}_{3}$; EtOH; TEA; reflux, (iv) 3-amino-5-pyrazolone; EtOH; TEA; r.t., (v) Ar-CH=C(CN) 2 ; EtOH; TEA; reflux, (vi) $\mathrm{CH}_{2}(\mathrm{CN})_{2}$; EtOH; TEA; reflux, $\left(\right.$ vii) $\mathrm{NH}_{2} \mathrm{NH}_{2} . \mathrm{H}_{2} \mathrm{O}$; EtOH; TEA, (viii) $\mathrm{NH}_{2} \mathrm{CXNH}_{2}$; EtOH; TEA.

In the present work and under the previous conditions, reaction of aldehyde $\mathbf{2 0}$ with chlorosulfonyl isocyanate (CSI) in dry benzene at $0-5{ }^{\circ} \mathrm{C}$ afforded the new $\mathrm{N}$-(chlorosulfonyl)- $\mathrm{N}-((2-$ oxo- $2 H$-chromen-6-yl)formamidine (21) (Scheme 3). Compound 21 give positive sulfur and chlorine tests as a chemical evidence, besides IR and mass spectrum.

On the other hand, the reaction of 6-amino coumarin (19) with chlorosulfonyl isocyanate in dry benzene at $0-5{ }^{\circ} \mathrm{C}$ gives 1 ( $N$-sulfonylchloride)-3-(2-oxo-2H-chromen-6-yl) urea (22), which on cyclization with an aluminum chloride (Lewis acid) gave the corresponding 2,7-dioxo pyrano(3,2-f)[1,3,4]benzothiazine-5,5dioxide (23) (Scheme 3).

In order to obtain new $N$-sulfonamide derivatives, compound 19 allowed to react with 4-bromo and 4-chloro benzene sulfonyl chloride under reflux in dry 1,4-dioxane containing few drops of triethylamine to give compounds $\mathbf{2 4 a , b}$, which upon reaction with chlorosulfonyl isocyanate in dry benzene at $0-5{ }^{\circ} \mathrm{C}$ yielded $N$-sulfonylchloride derivatives 25a,b. The freshly prepared 25a,b were cyclized using aluminium chloride to give the corresponding thiadiazine derivatives 26a,b (Scheme 3) 


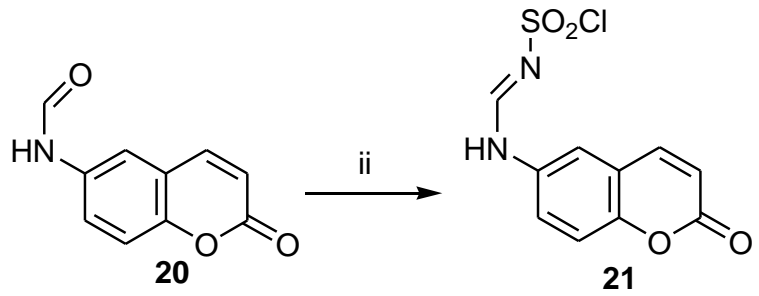<smiles>[X]c1ccc(S(=O)(=O)[O-])cc1</smiles>

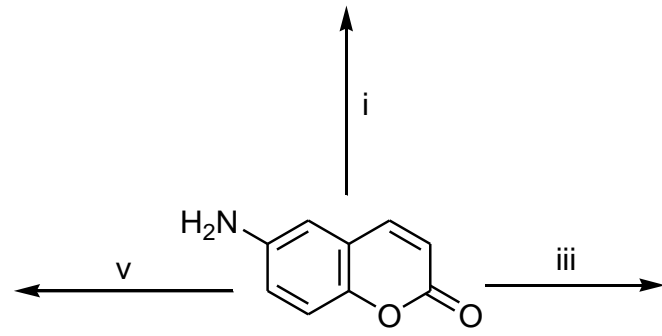<smiles>O=C(Nc1ccc2oc(=O)ccc2c1)NS(=O)(=O)Cl</smiles>

24

19

22<smiles>CC1CCCCC1</smiles><smiles>[X]c1ccc(S(=O)(=O)N(C(=O)NS(=O)(=O)OCc2ccccc2)c2ccc3oc(=O)ccc3c2)cc1</smiles><smiles>[X]c1ccc(SN2C(=O)NS(=O)(=O)c3cc4oc(=O)ccc4cc32)cc1</smiles>

iv<smiles>O=C1Nc2ccc3oc(=O)ccc3c2S(=O)(=O)N1</smiles>

23

24, 25, 26, $\mathrm{X}, \mathrm{a}=\mathrm{Br} ; \mathrm{b}=\mathrm{Cl}$

Scheme 3: reagents and conditions: (1) $\mathrm{HCOOH}$; reflux, (Morgan and Micklethwait 1904), (ii) CSI; dry benzene; 0-5 ${ }^{\circ} \mathrm{C}$; stirring, (iii) CSI; dry benzene; $0-5$ ${ }^{\circ} \mathrm{C}$, (iv) $\mathrm{AlCl}_{3}$, dry benzene; reflux, (v) $\mathrm{XC}_{6} \mathrm{H}_{4} \mathrm{SO}_{2} \mathrm{Cl}$; 1,4-dioxan; TEA, (vi) CSI; dry benzene; $0-5{ }^{\circ} \mathrm{C}$; stirring, (vii) $\mathrm{AlCl}_{3}$, dry benzene; reflux

\section{Biological activity results}

The non-cytotoxic tested compounds $4,5,8,12,13$ and 14 against hepatocellular carcinoma cells (HepG2) (Figure 1) significantly inhibited MMP-2 activity at $p$ value $<0.001$ except $\mathbf{8}$ and 12 at $p$ value $<0.05$ as a percent of control. All compounds exhibited high anti-migratory effect as revealed by transwel migration assay (number of migrated cells relative to control was
3.7, 3.3, 4.7, 3.4, 3.7, and 4.2 for compounds $\mathbf{4}, \mathbf{5}, \mathbf{8}, \mathbf{1 2}, \mathbf{1 3}, \mathbf{1 4}$, respectively (Figures 2a,b). Gene expression of IGF was not affected by any of the selected compounds (Figure 3). CD105 which is a surface marker was up regulated with all compounds except compound $\mathbf{4}$ which down regulated CD105. Compound 5 and $\mathbf{8}$ up-regulated the surface marker CD44, while other compounds had no effect on CD44 expression (Figure 4) 


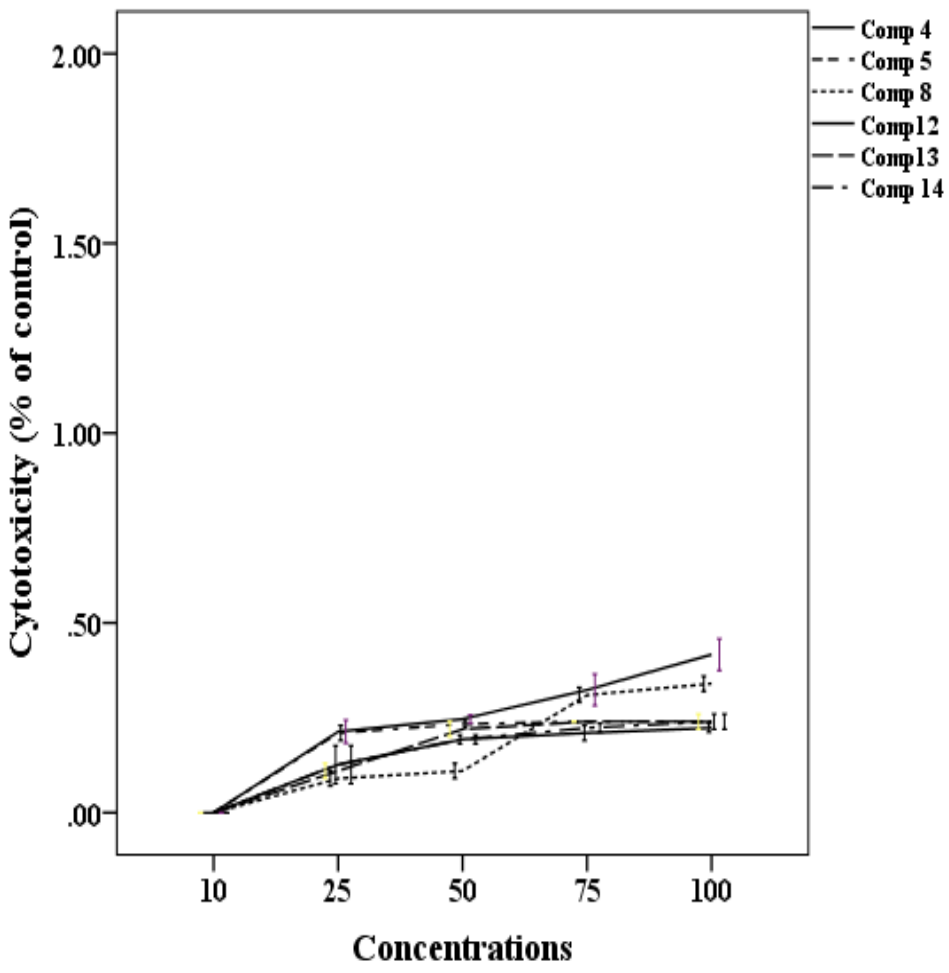

Fig. 1: Cytotoxic activity of the tested compounds against human hepatocellular carcinoma (HepG2) treated at various concentrations for $48 \mathrm{~h}$. Data were expressed as percent of control $\pm \mathrm{SE}(\mathrm{n}=3)$. Significantly different by Tukey's test $(\mathrm{p}<0.05)$.

\section{Biological activity discussion}

Anti-angiogenic therapies are promising for the treatment of cancer. Tumor metastasis is also regulated by angiogenes. In combination therapies, the efficacy of chemotherapy is enhanced by anti-angiogenic drug. The resistance to conventional cytotoxic therapeutics, emphasize the need for efforts to develop noncytotoxic targeted molecular therapies directed against the pathways involved in the angiogenesis.

Coumarin molecules can be utilized as lead compounds to develop potential nontoxic angiogenesis inhibitors (Namet al., 2002; Lee et al 2006). Generally, cells have been proposed to employ either protease-dependent (MMP-dependent) or proteaseindependent (MMP-independent) modes for migration and invasion (Wolf and Friedl, 2011). Many genes, proteins and pathways have been identified as potential targets for anti-angiogenic agents CD44; a transmembrane proteoglycan known to be expressed in most human cancers has been investigated as a therapeutic drug delivery target. CD105 (endoglin) is a proliferation-associated and hypoxia-inducible protein abundantly expressed in angiogenic endothelial cells (EC).
All the tested synthesized compounds showed non-cytotoxic effects against hepatocellular carcinoma cells (HepG2) (Figure 1), and exhibited high anti-migratory effect as revealed by transwel migration assay (Figure 2a, b). They also significantly inhibited MMP-2 activity except compounds $\mathbf{8}$ and 12. Gene expression of IGF was not affected by any of selected compounds. CD105 which is a surface marker was not involved in their anti-migrator activity where it was up-regulated with all compounds. In case of compound 4 the anti-migrator activity was mediated by down regulation of CD105. The surface marker CD44 was not involved in the anti-migratory activity induced by compound $\mathbf{5}$ and $\mathbf{8}$ where it was up-regulated, while other compounds had no effect on CD44 expression.

Compound 4 considered a promising anti-angiogenic agent where it exhibited MMP-dependent anti-migratory activity and down regulated CD105; however it has no effect on CD44.

The anti-migratory activity of the compounds which accompanied with up-regulation of CD44 is concomitant with that induced by docetaxel (DTX) treatment irrespective of the tumor type (Goldman et al., 2015). 

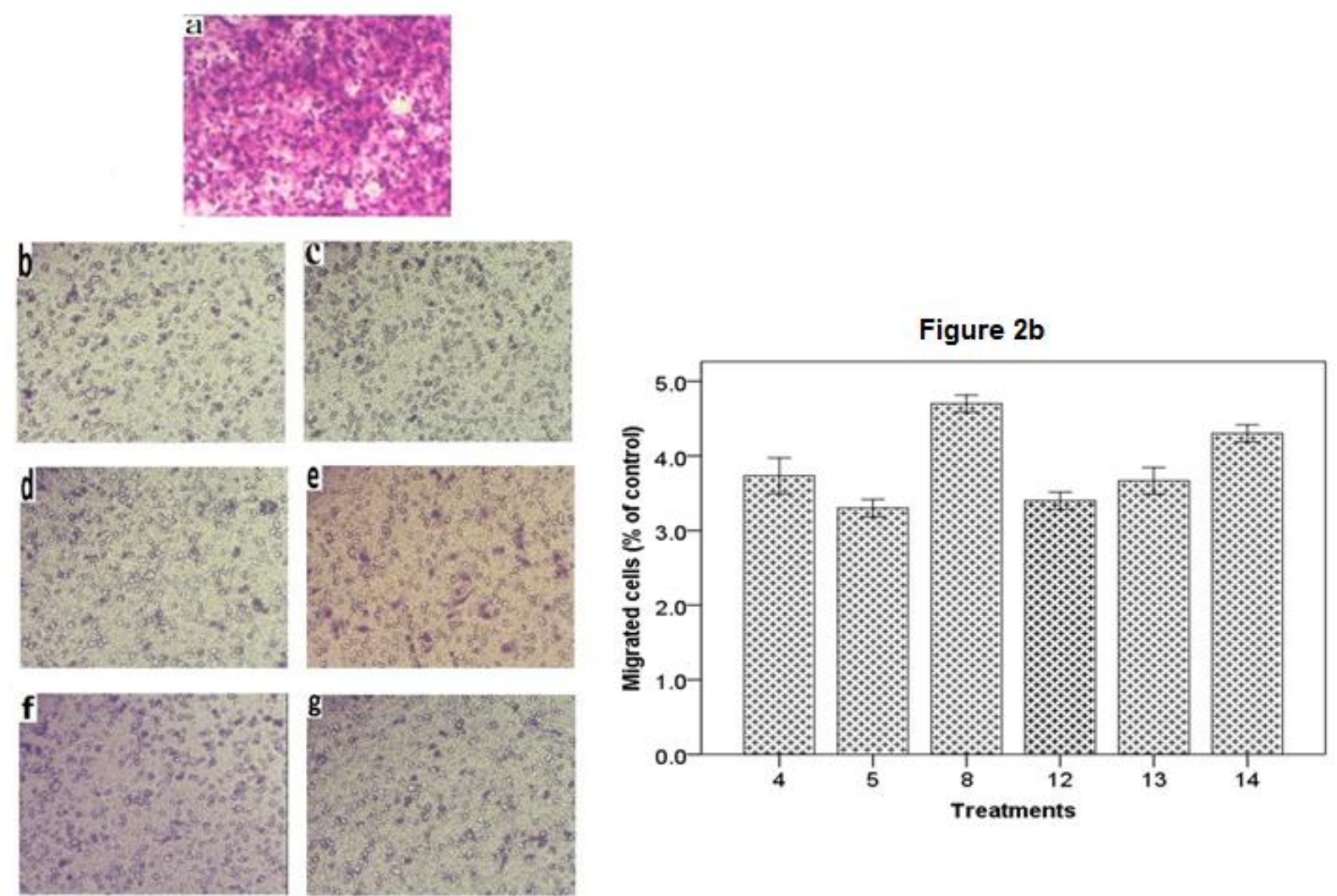

Figure 2a

Fig. 2: Migration of human hepatocellular carcinoma (HepG2) in response to treatment with the tested compounds. (A) Appearance of HepG2 cells (haematoxylin-eosine stained) on the underside of the membrane in the migration assay control. a: control, b: compound $\mathbf{4}$,c: compound $\mathbf{5}$, d: compound $\mathbf{8}$, e: compound 12, f: compound 13, g: compound 14. (B) Migrated cells percent in response to different treatments. Significantly different by Tukey's test ( $<<0.05$ )

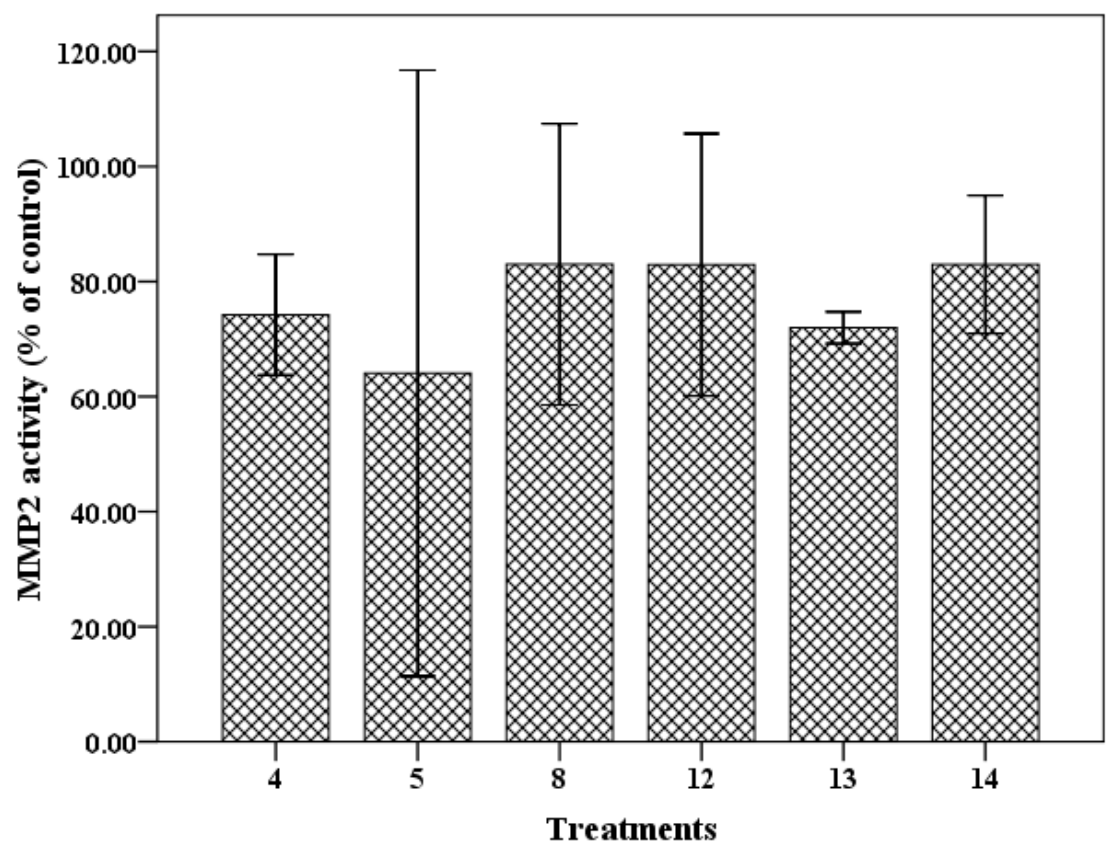

Fig. 3: Matrix metalloproteinase 2 of human hepatocellular carcinoma (HepG2) in response to treatment with the tested compounds. MMP-2 activity represented as percent of control. Significantly different by Tukey's test $(\mathrm{p}<0.05)$ 


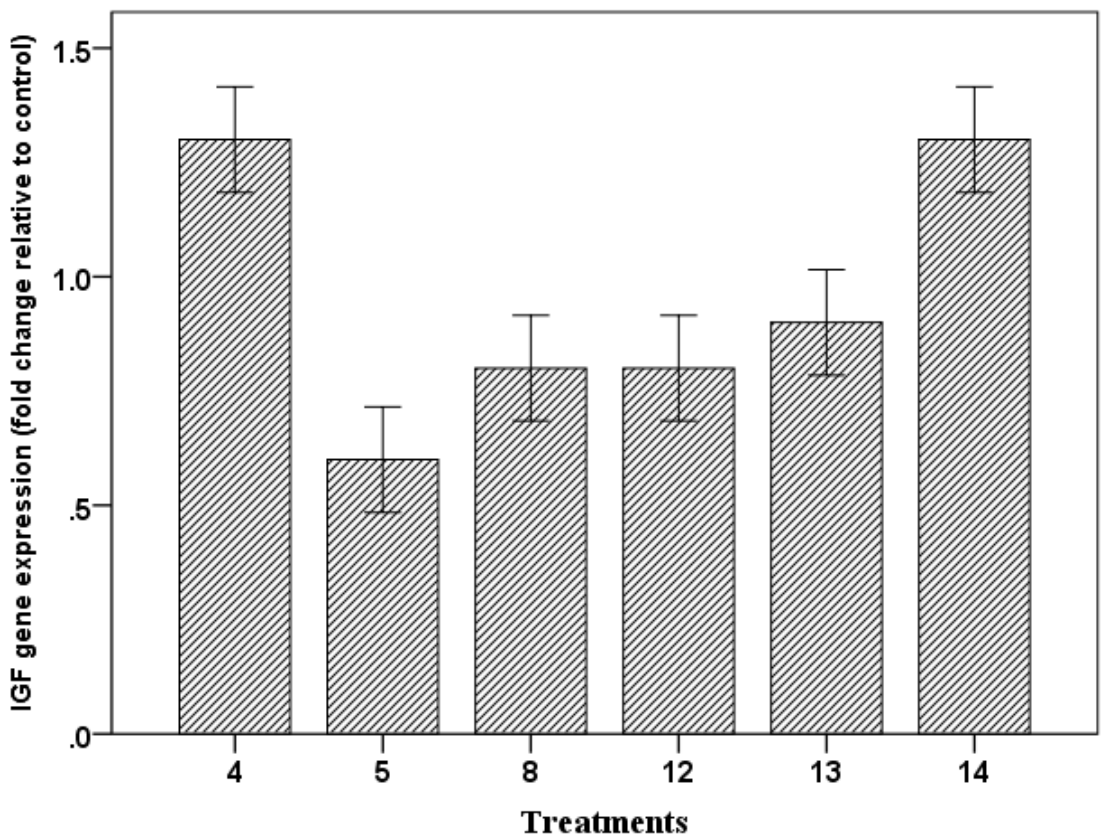

Fig. 4: Gene expression of insulin-like growth factor of human hepatocellular carcinoma (HepG2) in response to treatment with the tested compounds. Data was represented as fold change relatively to control. Significantly different by Tukey's test $(p<0.05)$

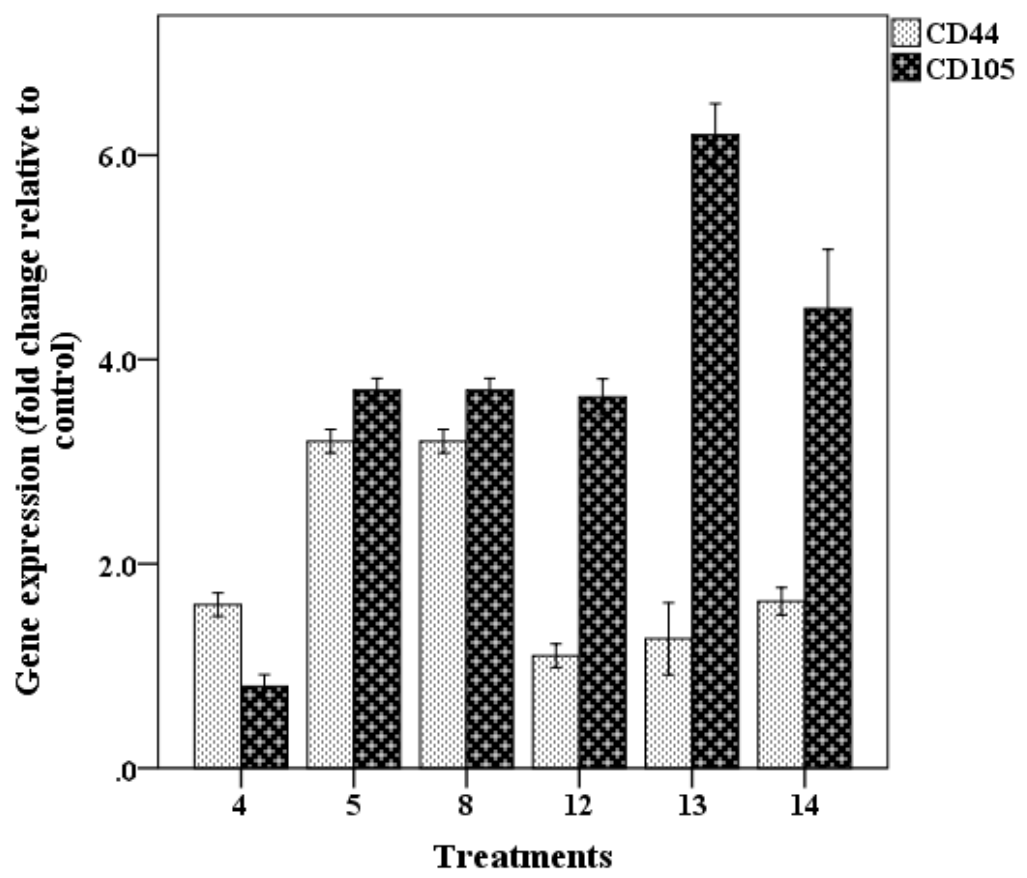

Fig. 5: Gene expression of surface markers CD44 and CD105 of human hepatocellular carcinoma (HepG2) in response to treatment with the tested compounds. Data was represented as fold change relatively to control. Significantly different by Tukey's test $(\mathrm{p}<0.05)$

\section{Molecular docking study}

MMP-2, a zinc-containing enzyme, plays an important role in cancer, by stimulating tumors growth, angiogenesisand metastasis, through its involvement in the degradation of extracellular matrix (Zapico et al., 2011) MMP-2 has been considered for many years an important target for the design of anticancer agents. For the coumarin derivatives 4, 5, 8, 12, 13 and
14 we first evaluated the suitability of these compounds to act as MMP-2 inhibitors by means of docking technique. There are not many experimental 3D structures of MMP-2 available on the protein data bank, PDB $1 \mathrm{HOV}$ being the only complex among MMP-2 catalytic domain with an inhibitor, hydroxamate $\mathbf{I 5 2}$. PDB $1 \mathrm{HOV}$ is an NMR structure composed of 11 models, and the superimposition of all of them showed no relevant changes around 
the ligand binding region. The previous studies of the binding mode of a set of putative MMP-2 inhibitors, including I52, showed no difference in the docking results performed on the 11 models, so we considered only model 1 to carry out the docking studies (Garcìa, 2007). The docking result showed that (Table 2), all docked compounds exhibit better docking score and good fitting inside the active side of MMP-2 (PDB: 1HOV) via formation of hydrogen bonds and coordination bonds with catalytic $\mathrm{Zn}^{++}$ion compare to co-crystalline ligand $\mathbf{I 5 2}$.

It has been observed that nitro coumarin derivatives $\mathbf{1 2}$, 13 and 14 were exhibited better docking score $(-28.17$ to $-18.81 \mathrm{~kJ}$ $\left.\mathrm{mol}^{-1}\right)$ than coumarin derivatives 4,5 and $\mathbf{8}(-16.22$ to $-13.82 \mathrm{~kJ}$ $\left.\mathrm{mol}^{-1}\right)$, and also higher than docking score of $\mathbf{I 5 2}\left(-18.18 \mathrm{~kJ} \mathrm{~mol}^{-1}\right)$. Also the presence of nitro group enhance the ability of compounds to coordinate with $\mathrm{Zn}^{++}$ion for example in case of compound 14, forms two coordination bonds with catalytic $\mathrm{Zn}^{++}$ion via two oxygen atoms of $\mathrm{SO}_{2}$ group and coumarin moiety while in case of compound 5 no interaction occur between the predicted binding pose and $\mathrm{Zn}^{++}$ion (Figures 6 and 7). On the other hand, it has been noticed that the anti-angogenic activity of the nitro compounds designed from postulation of molecular docking was not significant in-vitro. Only compound 4 with $\mathrm{N}$-acetylpyrazolone substitution at the 6-position of sulfonyl coumarin showed a promising anti-angiogenic activity, where exhibited good docking score of -16.22 compare to the MMP-2 inhibitor (I52) of -18.18 $\mathrm{kJmol}^{-1}$ (Table 2). Also, compound 4 showed better binding interaction with the active site of $1 \mathrm{HOV}$ via formation of a) one hydrogen bond acceptor between oxygen atom of $\mathrm{COCH}_{3}$ group

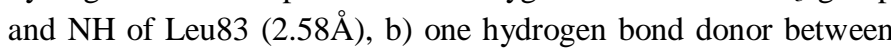
$\mathrm{NH}$ of acetyl pyrazolone ring and oxygen atom of Glu121 (1.45 $\AA$ ), c) coordination bond between oxygen atom of pyrazolone ring with catalytic $\mathrm{Zn}^{++}$ion (Table 2, Figures $8 \mathrm{a}, \mathrm{b}$ ).

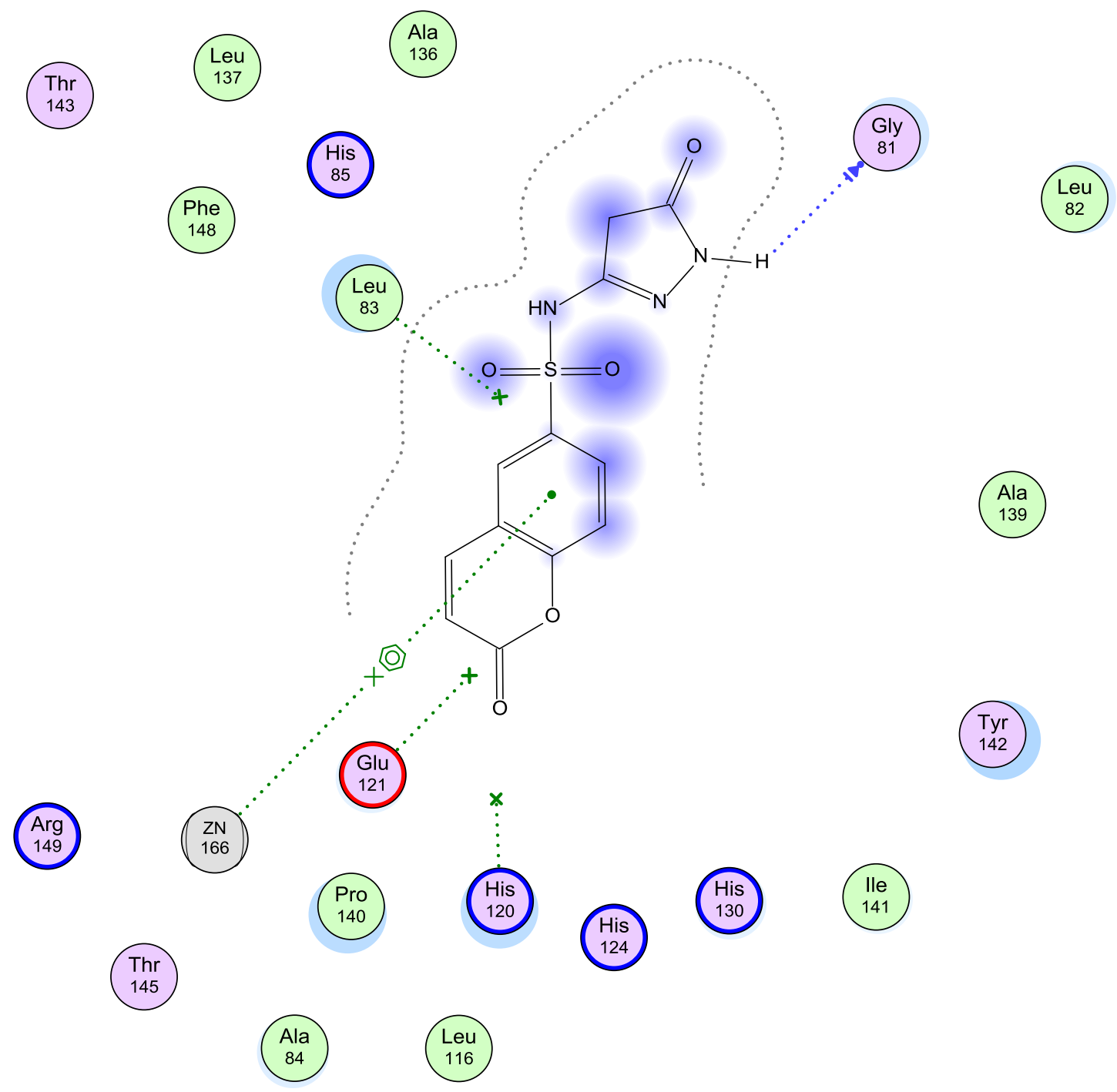

Fig. 6: The 2D depiction of the docked conformation of 5 into active side of MMP-2 (PDB ID: 1HOV). 


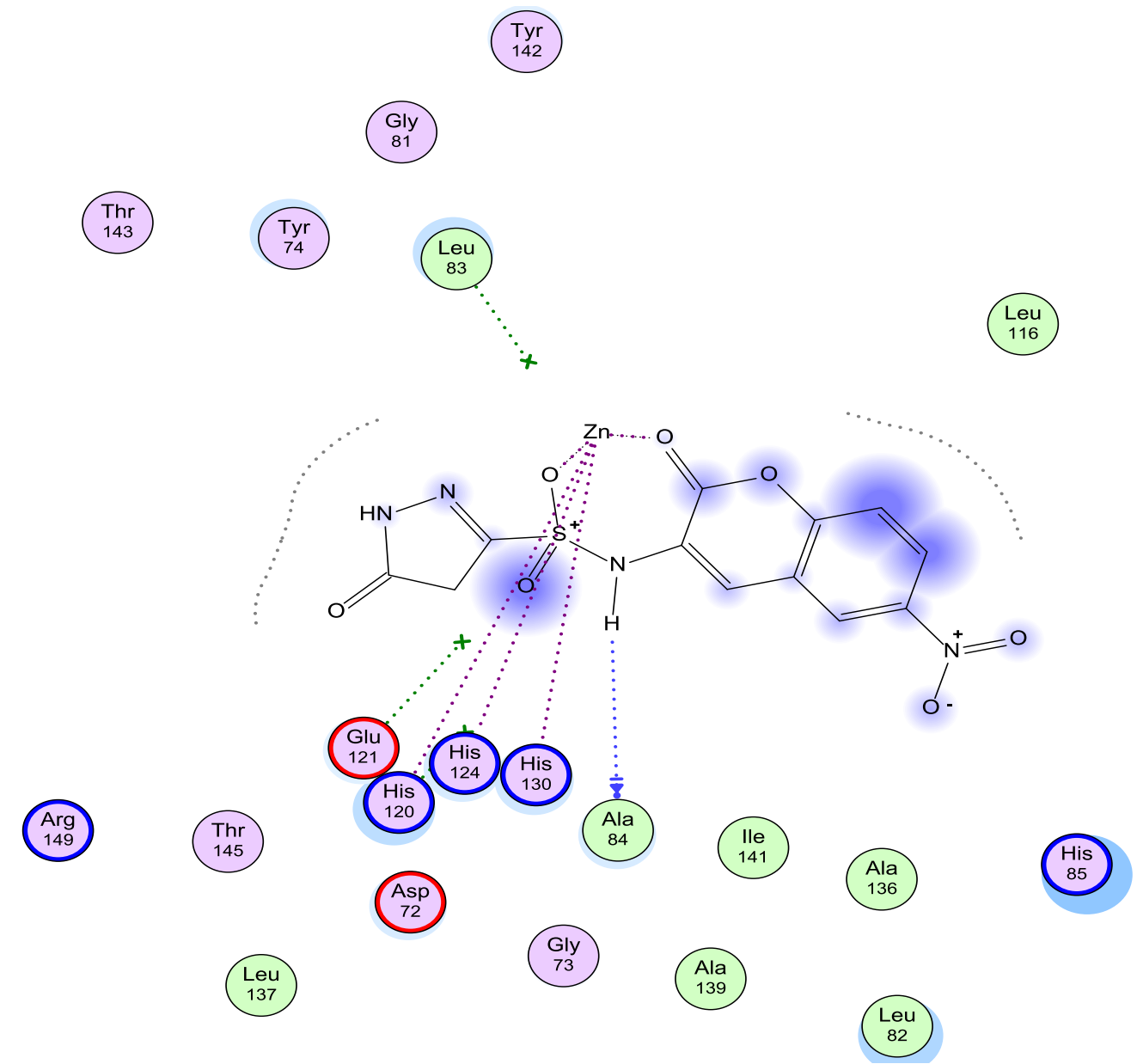

Fig. 7: The 2D depiction of the docked conformation of $\mathbf{1 4}$ into active side of MMP-2 (PDB ID: 1HOV).

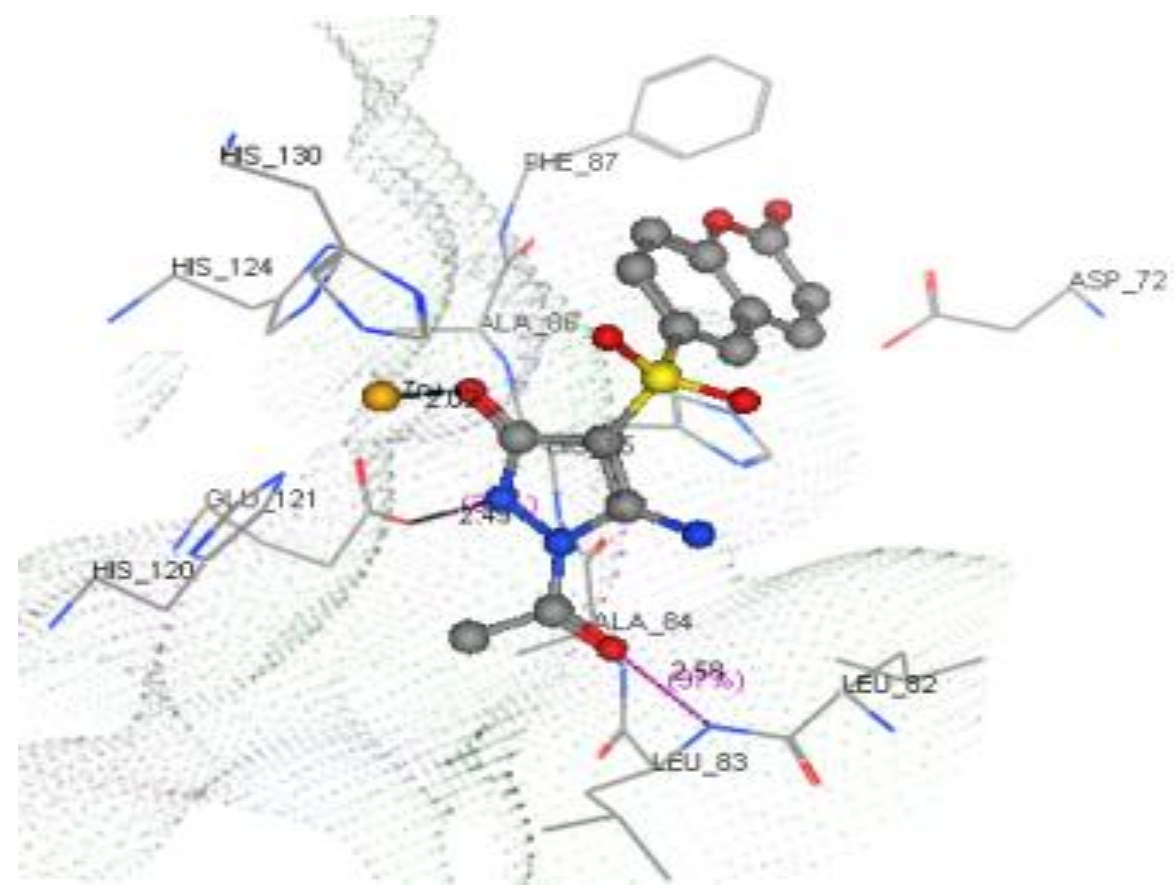

Fig. 8a: The 3D depiction of the docked conformation of $\mathbf{5}$ into active side of MMP-2 (PDB ID: 1HOV). 


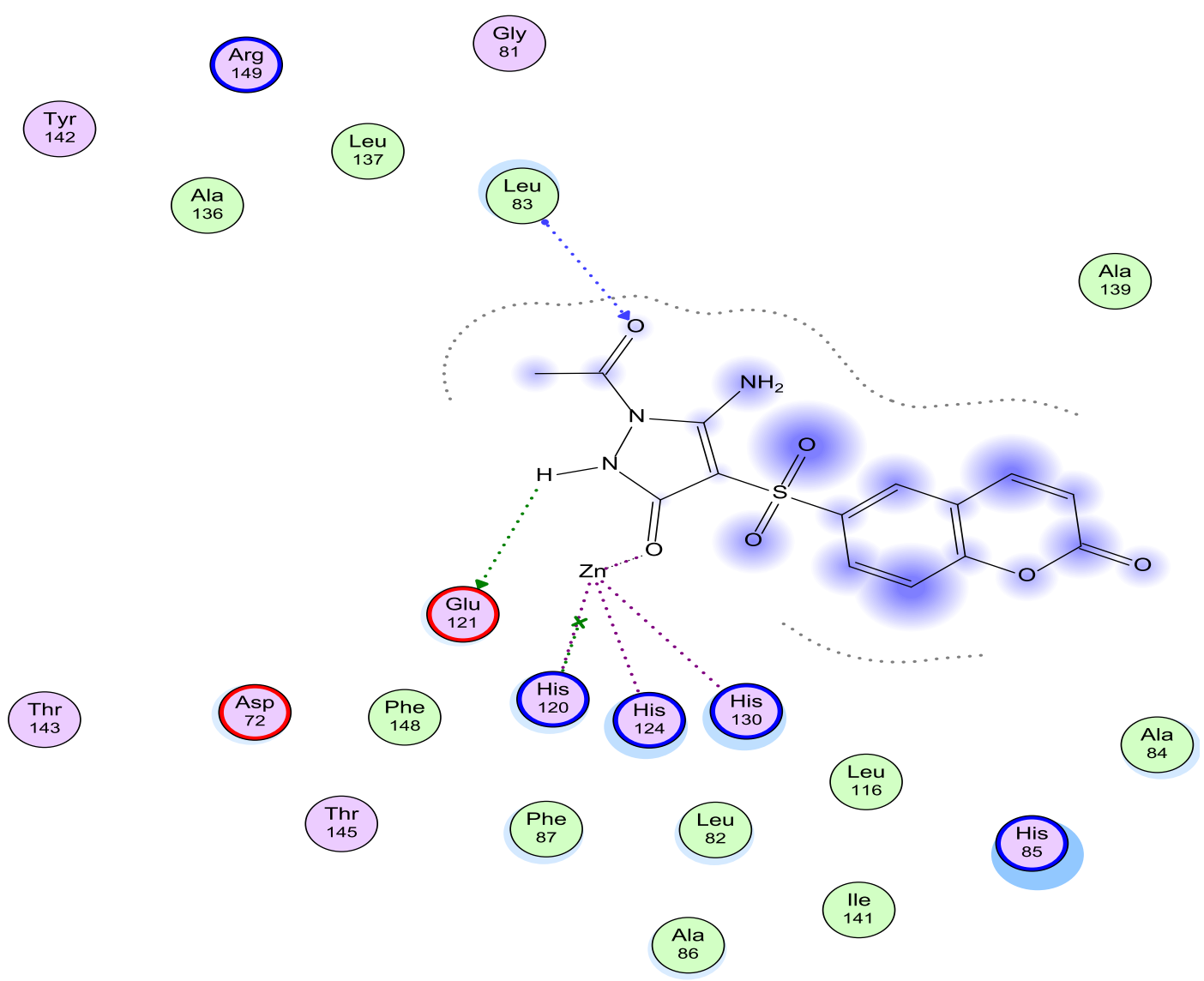

Fig. 8b: The 2D depiction of the docked conformation of 5 into active side of MMP-2 (PDB ID: 1HOV).

Table 1: List of primers genes.

\begin{tabular}{lll}
\hline Gene & Forward primer & Reverse primer \\
\hline GAPDH & 5'-ACCCACTCCTCCACCTTTGAC-3' & 5'-TGTTGCTGTAGCCAAATTCGTT-3 \\
CD105 & 5'-CTCTGCTGCTGAGCTGAATG-3 & 5'-GATCTGCATGTTGTGGTTGG-3 \\
CD44 & 5'-AGAAGGTGTGGGCAGAAGAA-3' & 5'-AAATGCACCATTTCCTGAGA-3' \\
IGF & 5'-GCAATGGGAAAAATCAGCAG-3' & 5'-GAGGAGGACATGGTGTGCA-3' \\
\hline
\end{tabular}

Table 2: Docking results of the most active compounds which docked with MMP-2 (PDB ID: 1HOV).

\begin{tabular}{|c|c|c|c|c|c|}
\hline $\begin{array}{c}\text { Compd. } \\
\text { No } \\
\end{array}$ & $\begin{array}{c}\text { Mol. Dock Score } \\
\left(\mathbf{k J ~ m o l}^{-1}\right)\end{array}$ & Type of bond & Atom of ligand involved & $\begin{array}{c}\text { Involved atom of } \\
\text { amino acid }\end{array}$ & $\begin{array}{l}\text { Length of } \\
\text { bond }\left(\AA^{\prime}\right) \\
\end{array}$ \\
\hline \multirow{4}{*}{$\mathrm{I} 52$} & \multirow{4}{*}{$\begin{array}{c}-18.18 \\
\operatorname{Rmsd}(1.04)\end{array}$} & H-don. & $\mathrm{OH}$ & N His120 & 3.41 \\
\hline & & H-don. & $\mathrm{HN}$ & O Glu 121 & 1.99 \\
\hline & & H-acc. & $\mathrm{O}$ of $\mathrm{SO}_{2}$ & N Leu83 & 3.05 \\
\hline & & Ionic & two hydroxamate oxygen atoms & $\mathrm{ZN}^{++}$ & $2.13 \& 2.08$ \\
\hline \multirow{3}{*}{4} & \multirow{3}{*}{-16.22} & H-acc. & $\mathrm{O}$ of $\mathrm{COCH}_{3}$ & $\mathrm{~N}$ of Leu83 & 2.58 \\
\hline & & H-don. & NH of acetyl pyrazolone & O of Glu 121 & 1.45 \\
\hline & & Ionic & $\mathrm{O}$ of pyrazolone & $\mathrm{Zn}^{++}$ & 2.03 \\
\hline 5 & -14.41 & H-don. & $\mathrm{NH}$ of pyrazolone & O of Gly81 & 1.65 \\
\hline \multirow{4}{*}{8} & \multirow{4}{*}{-13.82} & H-don. & NH of pyrazole & O of Ala84 & 1.39 \\
\hline & & H-don. & $\mathrm{NH}$ of pyrazole & O of Glu121 & 1.35 \\
\hline & & H-acc. & $\mathrm{O}$ of $\mathrm{SO}_{2}$ & NH of Leu83 & 2.89 \\
\hline & & Ionic & Two nitrogen atoms of pyrazole & $\mathrm{Zn}^{++}$ & $2.62 \& 2.10$ \\
\hline \multirow{2}{*}{12} & \multirow{2}{*}{-28.17} & H-don. & NH of pyrazolone & O of Glu 121 & 1.62 \\
\hline & & Ionic & $\mathrm{O}$ of $\mathrm{SO}_{2} \& \mathrm{O}$ of coumarin moiety & $\mathrm{Zn}^{++}$ & $2.67 \& 2.04$ \\
\hline 13 & -21.42 & Ionic & $\mathrm{O}$ of $\mathrm{COCH}_{3}$ & $\mathrm{Zn}^{++}$ & 2.15 \\
\hline \multirow{2}{*}{14} & \multirow{2}{*}{-18.81} & H-don. & $\mathrm{NH}$ of $\mathrm{SO}_{2} \mathrm{NH}$ & O of Ala84 & 2.06 \\
\hline & & Ionic & $\mathrm{O}$ of $\mathrm{SO}_{2}$ and $\mathrm{O}$ of coumarin moiety & $\mathrm{Zn}^{++}$ & $2.92 \& 1.99$ \\
\hline
\end{tabular}




\section{CONCLUSION}

Our study aimed to synthesize new non-cytotoxic sulfonyl coumarin derivatives against hepatocellular carcinoma cells (HepG2) for further test as anti-angiogenic agents using migration assay and MMP-2 activity by ELISA. Collectively, our results indicate that, coumarin molecules $4,5,8,13$ and 14 can be utilized as lead compounds to develop potential non-toxic angiogenesis inhibitors and small molecular ligands to target (HepG2), which was in concomitant with molecular docking results. 1-Acetyl-5-amino-4-(2-oxo-2H-chromene-6-sulfonyl)-1,2dihydro-pyrazol-3-one (4) considered a promising anti-angiogenic agent, where it exhibited MMP-dependent anti-migratory activity and down regulated CD105.

\section{AKNOLEDGMENT}

The authors are grateful to Micro-analytical Unit, National Research Centre, Giza, Egypt for carrying out elemental analyses and spectral data.

\section{Financial support and sponsorship: Nil.}

Conflict of Interests: There are no conflicts of interest.

\section{REFERENCES}

Abd El-Hafez OM, Mandour AH, Khattab A, Nassar MIm Kubecy T. Synthesis of some new coumarin derivatives with evaluation of their antimicrobial activity. Egypt J Pharm Sci, 1994; 35(1-6): 113-26.

Al Bayati RI, Al Amiery AAH, Al Majedy YK. Design synthesis and bioassay of novel coumarins. African J Pure App Chem, 2010; 4: 74-86

Arora RK, Kaur N, Bansal Y, Bansal G. Novel coumarinbenzimidazole derivatives as antioxidants and safer anti-inflammatory agents. Acta Pharmaceutica Sinica B, 2014; 4: 368-75.

Bankovskis J, Cirule M, Brusilovskii PI, Tsilinskaya IA. Synthesis of 5-alkylthio-8-hydroxyquinolines. Chem Heterocyclic Comp, 1979; 15: 1205-7.

Biddle A, Gammon L, Fazil B, Mackenzie IC. CD44 staining of cancer stem-like cells is influenced by down-regulation of CD44 variant isoforms and up-regulation of the standard CD44 isoform in the population of cells that have undergone epithelial-to-mesenchymal transition. PLoS One, 2013; 8(2): e57314.

Callejo MJ, Lafuente P, Martin-León N, Quinteiro M, Seoane C, Soto JL. A convenient preparation of $[1,2,4]$ triazolo[ $[1,5-a]$ pyridines from acetohydrazide derivatives: Synthetic and mechanistic aspects. J Chem Soc Perkin Trans 1, 1990; 1687-90.

Cesca M, Bizzaro F, Zucchetti M, Giavazzi R. Tumor delivery of chemotherapy combined with inhibitors of angiogenesis and vascular targeting agents. Front Oncol, 2013; 3: 259 (1-7).

Curini M, Epifano F, Maltese F, Marcotullio MC, Gonzales SP, Rodriguez JC. Synthesis of collinin an antiviral coumarin. Aust J Chem, 2003; 56: 59-60.

Dhar DN, Murthy KSK. Recent advances in the chemistry of chlorosulfonyl isocyanate. Synthesis, 1986; 1986(6): 437-49.

Feng Y, Likos JJ, Zhu L, Woodward H, Munie G, McDonald JJ, Stevens AM, Howard CP, De Crescenzo GA, Welsch D, Shieh H$\mathrm{S}$, Stallings WC. Solution, structure and backbone dynamics of the catalytic domain of matrix metalloproteinase-2 complexed with a hydroxamic acid inhibitor. Biochim Biophys Acta, 2002; 1598: 10-23.

Folkman J. Angiogenesis: an organizing principle for drug discovery?. Nat Rev Drug Discov, 2007; 6: 273-86.
Garcìa MA. University of San Pablo-CEU, Madrid, PhD Thesis

2007.

Goldman A, Majumder B, Dhawan A, Ravi S, Goldman D, Kohandel M, Majumder PK Sengupta, S. Temporally sequenced anticancer drugs overcome adaptive resistance by targeting a vulnerable chemotherapy-induced phenotypic transition. Nat Commun, 2015; 6: 6139 (1-13).

Graham B, Porter HD, Weissberger A. Investigation of pyrazole compounds VIII. Synthesis and acylation of pyrazolones derived from hydrazine and methylhydrazine. J Am Chem Soc, 1949; 71:983-8.

Heibron I. Dictionary of organic compounds. 4th ed. New York: Oxford University Press; 1965.

Idbaih A, Ducray F, Rio MSD, Hoang Xuan K, DelattreJ-Y. Therapeutic application of noncytotoxic molecular targeted therapy in gliomas: growth factor receptors and angiogenesis inhibitors. The Oncologist, 2008; 13: 978-992.

Ismail II, Mandour AH, Omar MT. Coumarin-6-deravatives with potential biological activity. Bull NRC Egypt, 1989; 14(3): 179-90.

Jeon YJ, Jang JY, Shim JH, Myung PK, Chae JI. Esculetin, A coumarin derivative, exhibits anti-proliferative and pro-apoptotic activity in G361 human malignant melanoma. J Cancer Prev, 2015; 20: 106-12.

Kaminski G, Jorgensen WL. Performance of the AMBER94, MMFF94 and OPLS-AA force fields for modeling organic liquids. J Phys Chem, 1996; 100: 18010-13

Kassem EM, El-Sawy ER, Abd-Alla HI, Abdel-Mogeed D, ElSafty MM. Synthesis, antimicrobial, and antiviral activities of some new 5-sulphonamido- 8-hydroxyquinoline derivatives. Arch Pharm Res, 2012; 35: $955-64$

Keating GJ, O'Kennedy R. In The chemistry and occurrence of coumarins; O'Kennedy R, Thornes RD Eds.; John Wiley \& Sons West Sussex, England, 1997; pp. 23-64.

Kirsch G, Abdelwahab AB, Chaimbault P. Natural and synthetic coumarins with effects on inflammation. Molecules, 2016; 21: 1322-37.

Kostova I. Synthetic and natural coumarins as cytotoxic agents. Curr Med Chem Anti-Cancer Agents, 2005; 5: 29-46.

Lee S, Sivakumar K, Shin W-S, Xie F, Wang Q. Synthesis and anti-angiogenesis activity of coumarin derivatives. Bioorg Med Chem Lett, 2006; 16: 4596-9.

Ma J, Waxman DJ. Combination of anti-angiogenesis with chemotherapy for more effective cancer treatment. Mol Cancer Ther, 2008; $7: 3670-84$.

Morgan TM, Micklthwait FMG. CXXV.-6-Aminocoumarin. J Chem Soc, 1904; 85: 1230-3.

Mosmann T. Rapid colorimetric assay for cellular growth and survival: application to proliferation and cytotoxicity assays. J Immunol Meth, 1983; 65: 55-63.

Nam N-H, Kim Y, You Y-J, Hong D-H, Kim H-M, Ahna B-Z. Preliminary structure anti-angiogenic activity relationships of 4senecioyloxymethyl-6,7-dimethoxycoumarin. Bioorg Med Chem Lett, 2002; 12: 2345-8.

SahooJ, Mekap SK, Kumar PS. Synthesis, spectral characterization of some new 3-heteroaryl azo 4-hydroxy coumarin derivatives and their antimicrobial evaluation. J Taibah Uni Sci, 2015; 9: 187-95.

Shao Y, Chen H, Jiang X, Chen S, Li P, Ye M, et al. Low expression of lncRNA-HMlincRNA717 in human gastric cancer and its clinical significances. Tumour Biol, 2014; 35: 9591-5.

Ucuzian AA, Gassman AA, East AT, Greisler HP. Molecular mediators of angiogenesis. J Burn Care Res, 2010; 31: 158-75.

Vasudev NS, Reynolds AR. Anti-angiogenic therapy for cancer: current progress, unresolved questions and future directions. Angiogenesis, 2014; 17: 471-94.

Wolf K, Friedl P. Extracellular matrix determinants of proteolytic and non-proteolytic cell migration. Trends Cell Biol, 2011; 21, 736-744.

Zapico JM, Serra P, Garcìa-Sanmartìn J, Filipiak K, Carbajo R J, Schott AK, Pineda-Lucena A, Martìnez A, Martìn-Santamarìa S, 
Pascual-Teresa B, Ramos A. Potent "Clicked" MMP2 Inhibitors: Synthesis, Molecular Modeling and Biological Exploration. Org Biomol Chem, 2011; 9: 4587-99.

ZavršnikD, Muratović S, Makuc D, Plavec J, Cetina M, Nagl A, Clercq ED, Balzarini J, Mintas M. Benzylidene-bis-[4hydroxycoumarin] and benzopyrano-coumarin derivatives: synthesis, ${ }^{1} \mathrm{H} /{ }^{13} \mathrm{C}-\mathrm{NMR}$ conformational and X-ray crystal structure studies and in vitro antiviral activity evaluations. Molecules 2011; 16: 6023-40.

Zemel R, Bachmetov L, Ad-El D , Abraham A, Tur-Kaspa R. Expression of liver-specific markers in naïve adipose-derived mesenchymal stem cells. Liver Int, 2009; 29(9): 1326-37.

\section{How to cite this article:}

El-Sawy ER, Ebaid MS, Rady HM, Shalby AB, Ahmed KM, AboSalem HM. Synthesis and molecular docking of novel noncytotoxic anti-angiogenic sulfonyl coumarin derivatives against hepatocellular carcinoma cells in vitro. J App Pharm Sci, 2017; 7 (02): 049-066. 